\title{
Nanoparticle Characterisation of Traditional Homeopathically Manufactured Cuprum metallicum and Gelsemium sempervirens Medicines and Controls
}

\author{
Michel Van Wassenhoven ${ }^{1}$ Martine Goyens ${ }^{2}$ Etienne Capieaux ${ }^{3} \quad$ Philippe Devos $^{4}$ Pierre Dorfman ${ }^{5}$
}

${ }^{1}$ European Committee for Homeopathy, Brussels, Belgium

Address for correspondence Michel Van Wassenhoven, MD,

2 Pharmaceutical Association for Homeopathy, Wépion, Belgium

3 PhytoCap, Bioengineering, Namur, Belgium

Chaussée de Bruxelles, 128 b5, B-1190 Brussels, Belgium

${ }^{4}$ Unio Homoeopathica Belgica, Evergem, Belgium

${ }^{5}$ Centre Européen d'Informatique et d'Automation, Brussels, Belgium

(e-mail: michelvw@homeopathy.be).

Homeopathy 2018;107:244-263.

\begin{abstract}
Background Homeopathy is controversial due to its use of very highly diluted medicines (high potencies/dynamisations).

Methods We used a multi-technology approach to examine dilutions of two commonly used homeopathic medicines: an insoluble metal, Cuprum metallicum, and a soluble plant tincture, Gelsemium sempervirens, for the presence of nanoparticles (NPs) of original substance. The homeopathic medicines tested were specially prepared, according to the European pharmacopoeia standards. We compared the homeopathic dilutions/dynamisations with simple dilutions and controls.

Results Using Mass Spectrometry (Single Particle-Inductively Coupled Plasma-Mass Spectrometry) and Dynamic Light Scattering (DLS) we could not find the expected copper in the $4 \mathrm{cH}$ potentisation and could not confirm the results previously obtained by Chikramane et al (2010). For Gelsemium medicines, using sensitive chromatography (HPLC-UV) up to a dilution level of $6 \mathrm{dH}(3 \mathrm{cH}=$ dilution 10e-6), there was no significant difference in alkaloid content between a simple dilution and a homeopathic potency. For higher potentisations, however, NP tracking analysis findings revealed the presence of particles in all samples (except for pure water). The measurements showed large differences in particle quantities, mean particle sizes and standard deviations of the mean sizes between manufacturing lines of different starting material.

There was always more material in potentised medicines than in potentised pure water. Gelsemium yielded the largest quantity of material (36 times more than that from copper at the same potentisation, $30 \mathrm{cH}$ ). The shapes and the chemical composition of the material are differentiable between different medicines and controls.
\end{abstract}

received

January 24, 2017

accepted after revision

May 14, 2018

published online

August 25, 2018
Copyright @ 2018 The Faculty of Homeopathy
DOI https://doi.org/ $10.1055 / \mathrm{s}-0038-1666864$ ISSN $1475-4916$. 


\author{
Keywords \\ - nanoparticles \\ - Cuprum metallicum \\ - Gelsemium \\ sempervirens \\ - Silicea terra \\ - Argentum \\ metallicum \\ - Kalium muriaticum \\ - lactose \\ - water \\ - homeopathy \\ - potentisation \\ - dynamisation \\ - pharmacology
}

Conclusion Potentisation influences specifically the nature of NPs detected. This material demonstrates that the step-by-step process (dynamised or not) does not match with the theoretical expectations in a dilution process. The Avogadro/ Loschmidt limit is not relevant at all. It was not possible to reproduce the findings of Chikramane et al (2010) using inductively coupled plasma-mass spectrometry with copper. Copper NPs could not be detected at 4cH and above.
- mass spectrometry
- high-performance liquid chromatography
- dynamic light scattering
- nanoparticle tracking analysis
- zeta-potential
- scanning electron microscopy

\section{Introduction}

Homeopathic practitioners daily prescribe homeopathic preparations that patients take regularly. There is a need for an explanation of the nature of these medicines. The DynHom research programme has taken a comprehensive approach to this question using available modern technology.

Homeopathy is a traditional medicine that has been used worldwide for more than 200 years. Recent studies indicate that homeopathically prepared medicines (HMs) contain source nanoparticles (NPs), ${ }^{1-4}$ silicates, ${ }^{3,5,6}$ and other, less well-characterised structures. ${ }^{7}$ Recent systematic review work on randomised controlled trials confirmed that the medicines prescribed in individualised homeopathy may have small, specific, treatment effects. ${ }^{8,9}$ Nevertheless, sceptics continue to insist that HMs are mere placebos containing no active material in any form. ${ }^{10}$

This debate about plausibility and evidence ${ }^{11}$ can be settled by fundamental research. Some people have focused on the dilution of bulk source material beyond the Avogadro's number and have ignored the fact that the actual manufacturing process is more than simple dilution ${ }^{11}-$ it involves step-by-step potentisation (for water-soluble material), also called a 'dilution-dynamisation' process, which is described in the European pharmacopoeia. ${ }^{12}$ The potentisation process is performed here using a certified machine which normally provides 100 calibrated vertical shocks at each dilution. The dilution process may be 1 part of material for 9 parts of solvent (dHahnemannian or $\mathrm{xH}$ potency) or 1 part of material for 99 parts of solvent ( $\mathrm{cH}$ or cKorsakov potency). The containers are always of pharmaceutical grade soda-lime-silicate glass ISO-719, ISO4802-1, Ph-Eur 3.2.1. For Hahnemannian potencies, a new container is used at each step, whilst Korsakov potencies are prepared within the same container at each dilution step.

Nanotechnology researchers have begun to recognise similarities between the traditional manufacturing techni- ques of homeopathy using crude, mechanical abrasion and the top-down approaches for making nanostructures from insoluble source materials used in modern nanotechnology. ${ }^{1,2,4}$ The authors, using transmission electron microscopy and inductively coupled plasma atomic emission spectroscopy (ICP-AES), found irregularly shaped poly-dispersed source metal particles, in concentrations ranging from picograms to nanograms per millilitre, in six different commercially made metal HMs including copper.

Previous publications ${ }^{7,13-15}$ using nuclear magnetic resonance (NMR) relaxation have revealed the involvement of nanobubbles and/or NPs and/or nanometric superstructures in high potentisations.

The purpose of this exploratory study is to replicate and extend the characterisation of colloidal NP in homeopathically prepared Cuprum metallicum (copper source) following good pharmaceutical practice (GPP) in $4 \mathrm{cH}, 5 \mathrm{cH}, 6 \mathrm{cH}, 7 \mathrm{cH}$, $30 \mathrm{cH}$ and $200 \mathrm{cK}$ potencies compared with a solvent control, potentised lactose control, simply diluted copper control and other controls (silver, silica and potassium chloride) and to verify whether the specific NPs can be identified in $\mathrm{dH}, \mathrm{cH}$ and cK potentisations from a soluble mother tincture (MT) of a plant (Gelsemium), compared with solvent controls, simply diluted medicines and others.

\section{Materials and Methods}

\section{Rationale}

Anticipating a need to detect low concentrations of polydispersed NPs of different sizes, shapes, surface properties and composition, ${ }^{2}$ for the copper dilutions we initially used mass spectrometric technique (ICP-MS) but broadened our investigations using dynamic light scattering (DLS), zetapotential (ZP), nanoparticle tracking analysis (NTA), ${ }^{4}$ and finally scanning electron microscopy with energy-dispersive X-ray spectroscopy (SEM-EDS) aimed at imaging the NPs and determining their chemical composition. 
We chose copper as the initial source material for HMs because it has already been characterised by previous authors, ${ }^{1}$ because of the well-known role of copper in the mitochondrial enzyme cytochrome-c oxidase, ${ }^{16}$ and because there is an extensive homeopathic literature published on this homeopathic medicine, including a randomised controlled trial. ${ }^{17-30}$

We chose a plant tincture, Gelsemium sempervirens, as a soluble source material because there is a precise definition of the stock material, ${ }^{31}$ as well as an extended homeopathic literature including references to objective epigenetic changes caused by this homeopathic medicine. ${ }^{17-22,32-40}$

\section{Homeopathically Manufactured Medicines}

One manufacturing line of medicines and controls was made in the Delvenne pharmacy (2 Rue A. Bequet, 5000 Namur, Belgium). Our team was authorised to use their certified homeopathic laboratory which is protected by two validated (ISO 5) laminar flow systems (B75/180). No other activity took place in this laboratory during our work. Our pharmacist followed the European Pharmacopoeia, which describe precisely how the manufacturing process must be carried out in accordance with the homeopathic tradition. The triturations of copper were performed manually following the standardised checks and balances of GPP. We used monohydrated, moderately fine, Fagron lactose (particle $\times 50=245 \mu \mathrm{m}$, lot 14B19-B01-304032 Production: 10-042015 Exp. 2-2017 N 2445732 Authorisation nº46 IR 05297). The water used was deionised water drawn directly from the tap after having first run some off. The tip of the tap spigot went directly into a flask containing ethanol to avoid ambient contamination. Purifying apparatus was Millipore Milli-RX 45 series number FSDM 96292D. The brown pharmaceutical $30 \mathrm{cc}$ flasks used were soda-lime-silicate glass ISO-719, ISO4802-1; these had tight plastic drop-caps using a screwed polypropylene closure system PhEur 3.1.3 'Polyolefines'; $\mathrm{PN}^{*} 18^{*} \mathrm{~K}^{*} \mathrm{~S} 10.6$ of polypropylene homopolymer (PPH).

The pharmacist's equipment included a mask, protective glasses, shoe protection, a white apron, a head cap and gloves. Hands were washed meticulously before carrying out any operation; no perfume was used.

Fifty grams of copper powder was provided by Labotics company: Sigma 203122 lot \#MKBS 4830 Pcode 10018973 74 containing $99.999 \%$ pure metal. One hundred milligrams of copper was placed on a paper and 9,900 $\mathrm{mg}$ of lactose was weighed for the trituration. According to the method PhEur 4.1.2., the vehicle was added carefully in small quantities whilst grinding until the entire vehicle was incorporated. The duration of trituration was 1 hour to obtain a $1 \mathrm{cH}$ potentisation. The intensity of trituration was sufficient to ensure homogeneity, with a particle size after trituration not exceeding $100 \mu \mathrm{m}$. The result is an ultra-fine, dry powder with a final mass of $8,450 \mathrm{mg}$; the weight loss was due to adhesion on to the pestle and mortar (Slick porcelain mortar 145/6, $400 \mathrm{~mL}, 7.5 \mathrm{~cm}$ height/13.5 cm diameter. Porcelain pestle 4, $140 \mathrm{~mm}$; Avignon Ceramic; France).

After washing (first with common water and then twice rinsed with deionised water) and passivation (upside down
1 hour at $130^{\circ} \mathrm{C}$ ) of the mortar, pestle and spatula, the same process was performed starting with $100 \mathrm{mg}$ of the $1 \mathrm{cH}$ preparation and $9900 \mathrm{mg}$ of lactose, the result of which was $8749 \mathrm{mg}$ of $2 \mathrm{cH}$. Following the same procedure with $100 \mathrm{mg}$ of $2 \mathrm{cH}$ and $9,900 \mathrm{mg}$ of lactose, we then produced $8,722 \mathrm{mg}$ of $3 \mathrm{cH}$. From this step onwards, the mixture started solubilising in water. We decided to avoid the use of an alcoholwater mixture (as is usual in homeopathy) lest the alcohol altered the measurements; it might also add unwanted contaminants to the solution. All further steps were performed in washed and passivated $\left(130^{\circ}\right) 30 \mathrm{cc}$ glass containers (always new bottles twice rinsed with deionised water and kept for 1 hour upside down at $130^{\circ} \mathrm{C}$ ). Passivation is the traditional homeopathic name used for this kind of neutralisation process. The aim was to obtain 'passive walls' to prevent cross-contaminations.

A total of $0.2 \mathrm{~g}$ of $3 \mathrm{cH}$ was added to $19.8 \mathrm{~g}$ of water and dynamised $(100+/-2$ shocks in 2 seconds using a Labotics certified and validated dynamiser 'Dynamat' (LABOTICS bvba; Heidestraat 254, B-2070 Burcht, Belgium) to obtain a $4 \mathrm{cH}$ potency. Further dynamisations were produced by the same process, each time in a new container, adding $0.2 \mathrm{~g}$ of the previous dynamisation to $19.8 \mathrm{~g}$ of water to produce 5 $\mathrm{cH}, 6 \mathrm{cH}$ etc., up to $30 \mathrm{cH}$. To produce the $200 \mathrm{cK}$, the starting material was the $4 \mathrm{cH}$ potency but the following steps were carried out in the same calibrated container using a Korsakov machine (Labotics) that automatically emptied, refilled and dynamised the flask. The same proportion, one part of the previous concentration to 99 parts of solvent, was always maintained. When large quantities were needed for lyophilisation (SEM-EDS), we still used the same $30 \mathrm{cc}$ flasks. For example, to produce $400 \mathrm{cc}$ of $4 \mathrm{cH}$, we prepared 20 containers each containing $20 \mathrm{cc}$ of $4 \mathrm{cH}$. To produce $200 \mathrm{cc}$ of 200 $\mathrm{cK}$, we stopped the dynamiser at $199 \mathrm{cK}$ and then prepared 20 bottles of $20 \mathrm{cc}$ of $200 \mathrm{cK}$.

The potentised lactose controls were produced in the same way, including the three first trituration steps but starting from $10 \mathrm{~g}$ of pure lactose to produce the $1 \mathrm{cH}$. The simply diluted copper control was prepared following the same successive steps but without trituration (simple homogenisation: sugar and powder carefully mixed with the spatula) to produce the $0.01,0.0001$ and 0.000001 dilution of copper in lactose. Further dilutions were prepared in water but similarly without the dynamisation process (simply diluted: bottle moved carefully once upside down). The third control was simply the water solvent and additionally we prepared a pre-filtered (0.1- $\mu \mathrm{m}$ filter) water control.

In an attempt to avoid any effect of lactose particles on the measurements, a line of Cuprum metallicum 2, 3 and $4 \mathrm{cH}$ in water was prepared but starting immediately after the $1 \mathrm{cH}$ trituration. In this case, we could see a copper residue in the bottom of the $2 \mathrm{cH}$ container-the copper was not completely reduced to nanosize.

Impregnation of pillules size 6 with Cuprum metallicum 4 $\mathrm{cH}, 9 \mathrm{cH}$ and $30 \mathrm{cH}$ was performed using pillules 'granusorb 4S' : Labotics 4/2015, $\mathrm{N}^{\circ}$ pharmacie: 18111 , Lot $\mathrm{n}^{\circ} 1410174010$ $25 \mathrm{~kg}$ Exp, 10/2019 diameter $4 \mathrm{~mm}, 20$ granules per gram. An impregnation machine (I-Tronic) performed this operation. 
Twenty impregnated pillules were then dissolved in $20 \mathrm{~g}$ of water and dynamised as usual.

Each flask was labelled with the name of the product, including level of dilution or potentisation, lot number and name of the pharmacist. Before continuing with the next preparation, the bottle's identity was blinded and protected by aluminium foil.

For the Gelsemium preparations, we used standard percentages of alcohol mixed with water used as the solvent for the HPLC-UV, $250 \mathrm{~g}$ in $300 \mathrm{cc}$ glass containers; the Gelsemium MT also contains alcohol. For NTA and SEM-EDS of higher dilutions, the use of an alcohol/water mixture was avoided for the dilution or potentisation processes because alcohol interferes with these measurements. All steps were performed in washed and passivated glass containers of 30 cc. For the first dilution or potentisation ( $1 \mathrm{dH}), 6 \mathrm{~g}$ of MT was added to $14 \mathrm{~g}$ of solvent and dynamised $(100 \pm 2$ shocks in 2 seconds using a Labotics certified and validated dynamiser 'Dynamat'). To produce further potentisations, the same process was followed using a new container, adding $2 \mathrm{~g}$ of the previous dilution to $18 \mathrm{~g}$ of solvent to produce $2 \mathrm{dH}$ up to $6 \mathrm{dH}$. For the $\mathrm{cH}$ process, $0.6 \mathrm{~g}$ of MT was added to $19.4 \mathrm{~g}$ of solvent to produce $1 \mathrm{cH}$, followed by $0.2 \mathrm{~g}$ of the previous dilution added to $19.8 \mathrm{~g}$ of solvent to produce $2 \mathrm{cH}$ up to $30 \mathrm{cH}$. Note that in both cases ( $\mathrm{dH}$ or $\mathrm{cH}$ potentisations), the initial dilution step produced a higher concentration than 9:1 or 99:1-this is a requirement of the pharmacopoeia (European pharmacopoeia 1-1-5 method).

The simply diluted Gelsemium control was prepared following the same successive steps but without dynamisation (simple homogenisation) in water. A second control was potentised water solvent. These controls were compared with copper triturations/dynamisations/dilutions.

For the NTA and SEM-EDS measurements, the first dilutions/potentisations were not used because the alcohol content of the initial MT would interfere with the results. Five hundred millilitres of the MT Gelsemium sempervirens $\mathrm{HAB}$ (Root extract) was provided by Heel laboratory (Homeoden) in PET (polyethylene terephthalate) container Lot 548463, expiry date: 12/2018; 982 UH 911F34. From 3cH, no significant alcohol traces remained in the preparations. For HPLC-UV, we prepared MT, 1, 2, 3, 4, 5 and $6 \mathrm{dH}$; controls were simply diluted MT to obtain 10e-1, 10e-2, 10e-3, 10e-4, 10e5 and 10e-6. For NTA and lyophilisations (SEM-EDS), we selected representative samples of $4 \mathrm{cH}, 5 \mathrm{cH}, 6 \mathrm{cH}, 7 \mathrm{cH}, 30$ cH, 6 cK, 30 cK, 200 cK, 10e-8, 10e-10, 10e-12,10e-14, 10e-60, potentised water (solvent) $4 \mathrm{cH}, 5 \mathrm{cH}, 6 \mathrm{cH}, 7 \mathrm{cH}, 30 \mathrm{cH}$ in glass containers and potentised aqua pura $30 \mathrm{cK}$ prepared in PET containers.

\section{Randomisation and Blinding}

Each bottle's identity was blinded with aluminium foil. Measurements occurred in instalments. A limited, randomly selected, series of samples was presented at each session (maximum 15 authorized samples per session). The first author (M.V.W.) brought randomly selected samples to the laboratories and opened the bottles without removing the foil; after measurements, the foil was removed by the first author so that the results could be labelled. This was a compulsory pragmatic approach.

\section{Single Particle-Inductively Coupled Plasma-Mass Spectrometry for Metals}

This spectrometry technique was chosen because of its extreme sensitivity, based upon previous publications using this methodology. ${ }^{1-3}$ It is used officially in Belgium in the Nanorisk project (RT 10/05 SPF public health authorities, food chain and environment safety) and has also been used by CODA-CERVA (Veterinary and Agrochemical Research Centre), which is a Federal scientific research establishment. This method is more accurate than ICP-AES (Agilent Technologies 7700 Series ICP-MS like with an ASX-500 Series ICPMS Autosampler; Agilent Technologies, Santa Clara, California, United States).

\section{Dynamic Light Scattering}

Dynamic light scattering is aimed to detect NPs in a solution crossed by a laser stream. The particles' scattering allows them to be counted and their size determined. These measurements were performed at SYSMEX Company (EttenLeur, The Netherlands) which imports the Malvern Instruments in Europe. Using the Malvern Zetasizer Nano ZSP (DLS), all samples needed to be filtered using a $0.1-\mu \mathrm{m}$ filter before measurements were taken because any measurement without such filtration failed, producing no valid results. All measurements were performed three times. The DLS was required because single particle-inductively coupled plasma-mass spectrometry (SP-ICP-MS) was unable to detect the metal.

\section{Zeta-Potential}

Zeta-potential detects the electric potential existing around particles. Measurements were made at the SYSMEX Company using the Malvern Zetasizer Nano ZSP with an adapted cell pilot. In this case, no valid measurements result if samples are filtered because all particles must be present to produce significant ZPs. This methodology is required to investigate the nature of NPs.

The required attenuator value for copper $4 \mathrm{cH}$ preparation was only ' 8 ', for potentised lactose ' 7 ' was sufficient, while for copper $200 \mathrm{~K}$ and water solvent ' 10 ' was required (11 is full laser power) to obtain valid results.

\section{High-Performance Liquid Chromatography using UV Detector}

High-performance liquid chromatography using UV detector (HPLC-UV) detects, identifies and measures weight of molecules in a solution. The analyses were carried out at the UCL (Université Catholique de Louvain, Belgium) on a LaChrom Elite system from Merck Hitachi comprising a photodiode array detector, an autosampler and a quaternary pump, all controlled by LaChrom Elite software. For the analysis conforming to French pharmacopeia (FP 2002 '02-09-2013'Gelsemium PPH), the column used was a Lichrospher 100 C18e, $250 \times 4 \mathrm{~mm}$ packed with $5 \mu \mathrm{m}$ particles. Twenty microlitre samples were injected in the full loop injection 
mode. The column was eluted at a constant flow rate of $0.4 \mathrm{~mL} / \mathrm{min}$ using a butylamine:water:methanol solvent in a 0.1:22:78 ratio. Other analyses were performed following the method recommended by Extrasynthese on a Gemini (Phenomenex) C18, $150 \times 2 \mathrm{~mm}$ packed with $3 \mu \mathrm{m}$ particles. Twenty microlitre samples were injected in the full loop injection mode. The column was eluted at a constant flow rate of $0.3 \mathrm{~mL} / \mathrm{min}$ using a solvent comprising a 47:53 mixture of $0.01 \mathrm{M}$ sodium dodecyl sulphate $(\mathrm{pH} 2.5)$ and acetonitrile. Detection was carried out at a wavelength of $255 \mathrm{~nm}$. Gelsemine and sempervirine were used as references (Extrasynthese; Genay, France). Solvents were obtained from Merck (Darmstadt, Germany).

\section{Nanoparticle Tracking Analysis}

Nanoparticle tracking analysis (NTA) utilises the properties of both light scattering and Brownian motion to determine the number and particle size of substances in liquid suspension. This technology can only detect particles larger than $20 \mathrm{~nm}$. The wavelength used for these measurements was $488 \mathrm{~nm}$ (Malvern Instruments LTD Nanosight NS300; Sysmex, Ecustraat 11, 4879 NP Etten-Leur, The Netherlands).

\section{Lyophilisation Process}

Freeze-drying was performed at the UCL using 500 cc Duran glass balls. The solutions were firstly frozen to $-120^{\circ} \mathrm{C}$ in liquid nitrogen, then attached to the column of the lyophilisator (Labconco), producing a negative pressure in the ball. Slowly returning to room temperature, ice water sublimated and was aspired. This process was repeated several times. At the end, dry residual material was collected and weighed.

\section{Scanning Electron Microscopy with Energy-Dispersive X-Ray Spectroscopy}

We used the Tabletop Microscope TM3030Plus by Hitachi at the SYSMEX Company in Netherlands (Malvern Instruments LTD Nanosight NS300). In addition to imaging the sample, the interaction of the primary electron beam with atoms in the sample causes shell transitions that result in the emission of an X-ray photon having an energy characteristic of the parent element. Detection and measurement of this energy allow the elemental makeup of the sample to be determined (EDS). EDS can provide rapid qualitative and semi-quantitative analysis of the elemental composition to a sampling depth of 1 to $2 \mu \mathrm{m}$. The emitted X-rays can also be used to generate maps or line profiles that show the elemental distribution in a sample surface. We selected this technology rather than transmission electron microscopy because of the very small amounts of material needed for SEM.

The aim here is to determine the precise nature of the particles detected with NTA. Dry samples were produced after lyophilisation using a single glass $500 \mathrm{cc}$ round flask. Since this process is very protracted, we also tried a tray lyophilisator that allowed several processes to run simultaneously. For Cuprum metallicum 4cH, we provided $400 \mathrm{cc}$ (20 bottles containing each $20 \mathrm{cc}$ of the dynamisation). This quantity was reduced during the experiment because sufficient material could be obtained from smaller samples, $200 \mathrm{cc}$ ( 10 bottles containing $20 \mathrm{cc}$ of each potentisation) or even $100 \mathrm{cc}$ ( 5 bottles). The reason for using 10 flasks was to ensure that the samples were fully comparable (also with respect to silicates) with those utilised for NTA. This process was carried out in a new glass $500 \mathrm{cc}$ round flask washed twice with deionised water and dried at $130^{\circ} \mathrm{C}$ (the same process as that used for the bottles). Finally, free dry residue was collected. The SEM supports were made of carbon; to avoid measurement errors introduced by the carbon, the semi-quantitative measurements of the elements were taken from selected points avoiding empty parts of the grid.

\section{Statistical Analysis Methods}

For NTA, international standards were used to analyse the results (ASTM E2834-12[2012] Standard Guide for Measurement of Particle Size Distribution of Nanomaterials in Suspension by NTA). Means, standard error and standard deviation are given after three consecutive measurements. The one-factor ANOVA test was used to analyse the variance within groups of results (pspp-Gnu, Free Software Foundation). To compare the measurements between each other, a $t$ test was used. For DLS and ZP, three measurements were allowed to calculate particle mean size and minimum and maximum size. Values were validated when the poly dispersity index $\left(\mathrm{PDI}=[\text { standard deviation } / \text { mean }]^{\wedge} 2\right)$ did not exceed 0.7 and the intensity of the scattering was obtained without full laser power (always the case here). The device used was based on the International Standard on Dynamic Light Scattering ISO13321 (1996) and ISO22412 (2008). The $t$-tests were also used here. For EDS, the values were semiquantitative; cut-off values were under $1 \%$. To obtain correlated values, we put together percentage, amount of dry collected material and atomic mass of each atom. To avoid type I errors, the $p$-values have been compensated by the Bonferroni correction. Nevertheless, batch effects cannot be totally excluded.

\section{Results}

\section{Single Particle-Inductively Coupled Plasma-Mass Spectrometry}

In a pilot phase, we performed this analysis on Cuprum metallicum $4 \mathrm{cH}$ because a calibration was required for copper to correct for the presence of lactose particles in the water. Even though lactose cannot be detected by SP-ICP-MS, it would influence the results without this calibration. The lactose only enhanced the ICP-MS signal intensity and CODA-CERVA was able to correct for this by using a calibration standard in water containing the same percentage of sugar as the sample. Several attempts to measure copper in the liquid sample of Cuprum metallicum $4 \mathrm{cH}$ were made but failed. The limiting factor was actually the small size of the particles, the detection limit with SP-ICP-MS for copper particles being $45 \mathrm{~nm}\left(52 \mathrm{~nm}\right.$ for $\mathrm{Cu}_{2} \mathrm{O}$ ). Another attempt using $1.33 \mathrm{~g}$ of Cuprum $4 \mathrm{cH}$ dry lyophilised powder just solubilised in deionised water also failed. There was a huge background signal due to too small NPS to be identified but no copper particles of a size above $45 \mathrm{~nm}$. 


\section{Dynamic Light Scattering}

No verifiable detection of NPs was possible without initial filtration of the sample through a $0.1-\mu \mathrm{m}$ filter. There were no detectable particles in the water control, in Cuprum metallicum $5 \mathrm{cH}$ up to $30 \mathrm{cH}$ and $200 \mathrm{cK}$, in Lactose control $5 \mathrm{cH}$ up to $30 \mathrm{cH}$, pre- and post-filtered $(0.1 \mu \mathrm{m})$ water B control, Cuprum metalicum $3 \mathrm{cH}$ and $4 \mathrm{cH}$ from trituration $1 \mathrm{cH}$.

Particles were detected only in Lactose control $4 \mathrm{cH}$ (-Supplementary Fig. 1, available online only), Cuprum metallicum $4 \mathrm{cH}$ (-Supplementary Fig. 2, available online only), copper simply diluted at a level corresponding to $4 \mathrm{cH}$, Cuprum metallicum $2 \mathrm{cH}$ from trituration $1 \mathrm{cH}$ and diluted pillules impregnated with Cuprum metallicum $4 \mathrm{cH}$ (-Supplementary Fig. 3, available online only).

The mean NPs size, smaller in pure lactose $4 \mathrm{cH}$ control, might suggest that when copper has been diluted or triturated in lactose, there is something more but DLS does not allow a significant differentiation between the samples (-Table 1). Nevertheless, the PDI (-Supplementary Fig. 4, available online only) of the DLS measurements confirms these values. The particle size distribution of Cuprum $4 \mathrm{cH}$ is more consistent than in controls.

\section{Zeta-Potential}

We could observe a difference in ZP between water control and all other unfiltered samples ( - Fig. 1, - Supplementary
Fig. 5 [available online only]). The lactose control $4 \mathrm{cH}$ may be differentiated from Cuprum metallicum $4 \mathrm{cH}$ samples but not from the Cuprum metallicum $200 \mathrm{cK}$ sample. The validity (number of counts) of the measurements is the highest for the Cuprum $4 \mathrm{cH}$ sample. The electrical charge around particles, measured with DLS, could allow the water control to be discriminated from other preparations but this difference is not statistically significant. Nevertheless, the particles in HMs are surrounded by electric fields.

\section{High-Performance Liquid Chromatography using UV Detector}

Measurements were performed according to two different protocols. The first followed the modus operandi described in the French pharmacopoeia (FP-Gelsemium PPH 2002/0209-2013) that allowed the quantification only of gelsemine, whilst the second followed the procedure given by Extrasynthese, which allows the quantification of both sempervirine (-Supplementary Fig. 6, available online only) and gelsemine (-Supplementary Fig. 7, available online only). Sempervirine is the most toxic alkaloid from this plant (death ensues from respiratory failure ${ }^{31}$ ), while gelsemine is the required marker for the Pharmacopoeia (PhEur).

High-performance liquid chromatography quantification of the alkaloids ( - Fig. 2 ) showed no significant difference between a simple dilution and a homeopathic potentisation

Table 1 Particles mean sizes measured with DLS (three measures), in filtered samples: the difference between dynamised lactose control $4 \mathrm{cH}$, Cuprum $4 \mathrm{cH}$, Cuprum simply diluted $10 \mathrm{e}-8$ and Cuprum $2 \mathrm{cH}$ from trit $1 \mathrm{cH}$ is not significant

\begin{tabular}{|l|l|l|l|l|l|}
\hline & $\begin{array}{l}\text { Lactose control } \\
\text { 4cH }\end{array}$ & Cuprum 4cH & Sucrose & Cuprum 10e-8 & $\begin{array}{l}\text { Cuprum 2CH from } \\
\text { Trit 1cH }\end{array}$ \\
\hline Size min (nm) & 1.234 & 1.404 & 0.756 & 1.477 & 1.353 \\
\hline Size ‘SD-90’ (nm) & 0.778 & 0.894 & 0.459 & 0.908 & 0.924 \\
\hline Size average (nm) & 1.284 & 1.422 & 0.765 & 1.499 & 1.48 \\
\hline Size ‘SD+90' (nm) & 1.79 & 1.95 & 1.071 & 2.08 & 2.036 \\
\hline Size max (nm) & 1.316 & 1.442 & 0.77 & 1.529 & 1.544 \\
\hline$p$-Values & Vs. Cupr, 0.7437 & & Vs. Cupr, 0.1152 & Vs. Cupr, 0.8380 & Vs. Cupr, 0.8677 \\
\hline
\end{tabular}

Abbreviations: DLS, dynamic light scattering; Size 'SD \pm 90 ' nm, device measures above or under the peak of the curve.

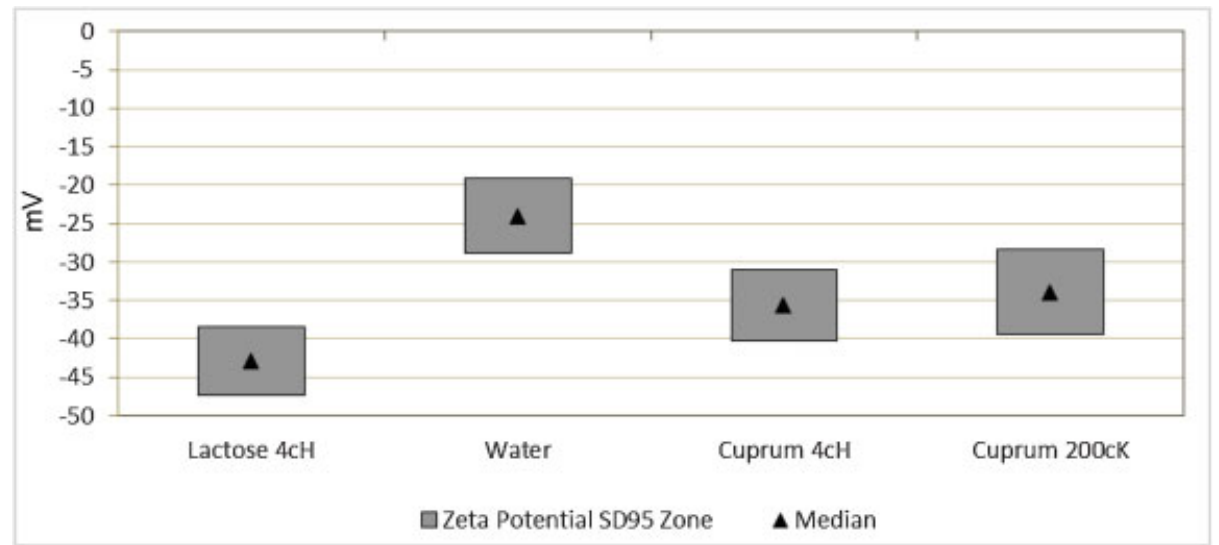

Fig. 1 Mean zeta-potential values $(-x \mathrm{mV})$ and measured standard deviation in $\mathrm{mV} 95 \%$ above or under the peak of the curve. The difference between water control and all other values is not significant (Water vs. Cupr $4 \mathrm{cH}, p=0.1591$; Water vs. Cupr 200K, $p=0.1061$ ). 


\section{2:Wavelength 243nm, Bandwith 4nm}

Time: 0,521003 Minutes-Amplitude: $0,06725 \mathrm{mAU}$

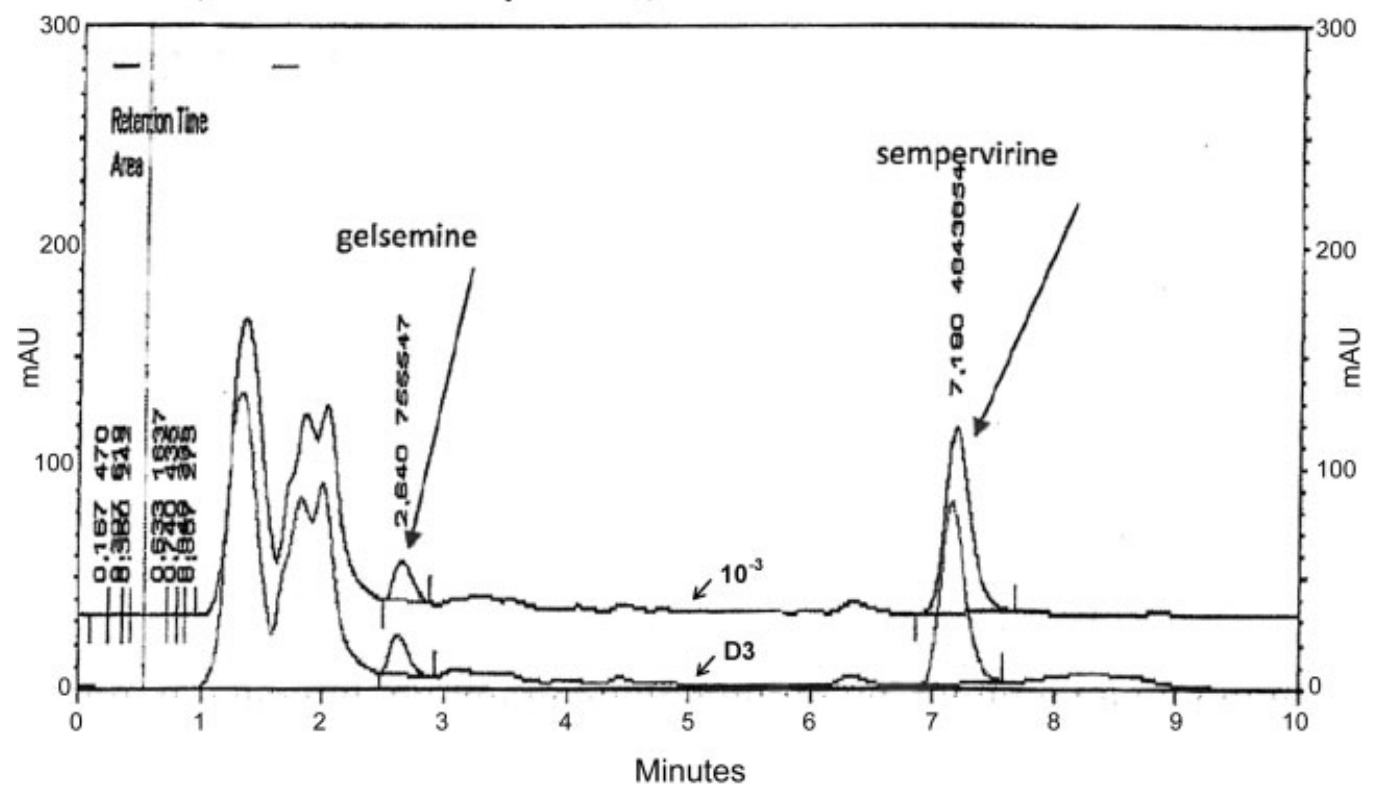

Fig. 2 High-performance liquid chromatography using ultra violet detector (HPLC-UV) chromatograms 3 dH potentisation and 10e-3 simple dilution. The HPLC-UV allows the concentration of two specific markers to be followed across time. As a control, two specially calibrated column were used, one for Gelsemine and one for Sempervirine.

process. The quantification limit for the alkaloids gelsemine or sempervirine is reached at $6 \mathrm{dH}(3 \mathrm{cH})$ ( - Table 2). At that level of dilution or potentisation, the alkaloids can still be detected but there are inconvenient interference peaks which prevent any accurate quantification. When following a step-by-step dilution by tenths, the quantities of markers detected are similar for simple dilution and for the dilution/dynamisation process. HPLC-UV of pure deionised water yields only a very little peak that absorbs in low UV wavelength.

\section{Nanoparticle Tracking Analysis}

We were not able to detect copper in the first soluble potentisation $(4 \mathrm{cH})$ with SP-ICP-MS, and with DLS there was no significant difference in detected NPs between filtered potentised lactose $4 \mathrm{cH}$ and filtered Cuprum metallicum $4 \mathrm{cH}$. Further analyses of the NPs are needed. The specific Gelsemium markers could not be quantified beyond the dilution level $10 \mathrm{e}-6(6 \mathrm{dH}$ or/and $3 \mathrm{cH})$ but still remained. The null hypothesis is that these NPs are disappearing during

Table 2 HPLC-UV quantification of sempervirine and gelsemine (alkaloid markers) (three measures)

\begin{tabular}{|l|l|l|}
\hline & Sempervirine & Gelsemine \\
\hline & (Mean \pm standard deviation) & (Mean \pm standard deviation) \\
\hline Mother tincture (dilution $50 \times$ ) & $577.1 \mu \mathrm{g} / \mathrm{mL} \pm 1.1$ & $354.0 \mu \mathrm{mL} \pm 1.5$ \\
\hline Mother tincture (dilution $20 \times$ ) & $577.5 \mu \mathrm{g} / \mathrm{mL} \pm 3.8$ & $360.2 \mu \mathrm{gL} \pm 0.3$ \\
\hline $1 \mathrm{dH}$ & $165.5 \mu \mathrm{g} / \mathrm{mL} \pm 1.7$ & $116.1 \mu \mathrm{g} / \mathrm{mL} \pm 1.7$ \\
\hline $10^{-1}$ & $179.0 \mu \mathrm{g} / \mathrm{mL} \pm 0.8$ & $111.6 \mu \mathrm{g} / \mathrm{mL} \pm 1.7$ \\
\hline $2 \mathrm{dH}$ & $16.1 \mu \mathrm{g} / \mathrm{mL} \pm 1.8$ & $15.5 \mu \mathrm{g} / \mathrm{mL} \pm 1.5$ \\
\hline $10^{-2}$ & $16.0 \mu \mathrm{g} / \mathrm{mL} \pm 2.5$ & $17.9 \mu \mathrm{g} / \mathrm{mL} \pm 5.1$ \\
\hline $3 \mathrm{dH}$ & $1.51 \mu \mathrm{g} / \mathrm{mL} \pm 1.8$ & $1.44 \mu \mathrm{g} / \mathrm{mL} \pm 2.2$ \\
\hline $10^{-3}$ & $1.56 \mu \mathrm{g} / \mathrm{mL} \pm 2.7$ & $1.44 \mu \mathrm{g} / \mathrm{mL} \pm 3.3$ \\
\hline $4 \mathrm{dH}$ & $0.117 \mu \mathrm{g} / \mathrm{mL} \pm 8.3$ & $0.115 \mu \mathrm{g} / \mathrm{mL} \pm 2.8$ \\
\hline $10^{-4}$ & $0.117 \mu \mathrm{g} / \mathrm{mL} \pm 5$ & $0.112 \mu \mathrm{g} / \mathrm{mL} \pm 2.7$ \\
\hline $5 \mathrm{dH}$ & $0.00722 \mu \mathrm{g} / \mathrm{mL} \pm 11.1$ & $0.01076 \mu \mathrm{g} / \mathrm{mL} \pm 11.2$ \\
\hline $10^{-5}$ & $0.00749 \mu \mathrm{g} / \mathrm{mL} \pm 2.4$ & $0.01074 \mu \mathrm{g} / \mathrm{mL} \pm 0.7$ \\
\hline $6 \mathrm{dH}$ & Non-quantifiable & Non-quantifiable \\
\hline $10^{-6}$ & Non-quantifiable & Non-quantifiable \\
\hline
\end{tabular}

Abbreviation: HPLC-UV, high-performance liquid chromatography using ultraviolet detector. 
further dilutions or potentisations. The NTA technique is used from a $10 \mathrm{e}-8$ dilution level $(4 \mathrm{cH})$. NTA revealed the presence of particles in all diluted or potentised samples (-Tables 3-7). No particles were found in the pure water control. For copper, the controls used were simply diluted copper, potentised copper in PET containers and dynamised lactose. Three successive measurements were performed for each sample. The controls used for Gelsemium sempervirens were simply diluted stock, potentised water in the glass containers and potentised water in PET containers. Three successive measurements were performed for each sample.

For copper, particles count in each frame of the viewing device ( - Table 3 ) revealed a significant difference in number of particles between simple dilutions, $\mathrm{cH}$ preparations and $\mathrm{cH}$ lactose control. Smallest numbers were reported for the copper $\mathrm{cH}$ HMs. The $6 \mathrm{cH}$ could not be discriminated from $6 \mathrm{cK}$ but at higher dilution/dynamisation level became significant. The differences in particles number/frame during the manufacturing process of the different stocks are mostly relevant, smallest numbers and decreasing in the copper $\mathrm{cH}$ process, unstable for simply diluted process and $\mathrm{cH}$ lactose control.

For Gelsemium (-Table 4), particles count in each frame of the viewing device revealed a significant difference in number of particles between simple dilutions, $\mathrm{cH}$ preparations and $\mathrm{cH}$ aqua control. Exceptions to this rule is the $30 \mathrm{cH}$ level were no difference can be observed. Smallest numbers being the simple dilution this time. For this manufacturing process, we stressed that the observed quantities were mostly under 1 particle by frame and this was the limit of acceptance for this device. The difference in particles number of particles during the manufacturing process of the different stocks was variable; mostly not significant for the aqua control. These numbers were almost stable within the same manufacturing process.

Mean sizes of particles in simply diluted copper ( $\mathbf{- T a b l e ~} \mathbf{5}$, -Supplementary Fig. 8, available online only) were significantly smaller than in corresponding $\mathrm{cH}$ potentisations and $\mathrm{cH}$ copper particle size could be discriminated from the dynamised lactose control. Particles in simply diluted successive copper samples were not significantly different in size but a difference appeared when we compared samples with greatly differing dilutions (e.g. compared low dilutions with very high dilution samples). All preparations in PET containers could not be discriminated in size from each other. Size of particles in cK potentisations was smaller than in $\mathrm{cH}$ preparations. Between $\mathrm{cK}$ dynamisations, there was no difference in size between $6 \mathrm{cK}$ and $30 \mathrm{cK}$ but in higher potentisations particles were significantly smaller than in all other preparations including simply diluted samples. Mean sizes were mostly above $100 \mathrm{~nm}$.

Mean sizes of particles in Gelsemium (simply diluted or potentised $\mathrm{cH} / \mathrm{cK}$ ) and in the control dynamised pure water could not be discriminated from each other ( $\mathbf{-}$ Table $\mathbf{6}$,

-Supplementary Fig. 8, available online only).

The final aim of these measurements was to compare the detected NPs in Cuprum metallicum HMs and in Gelsemium HMs (-Table 7). We analysed the number of particles and their mean sizes including the SD on the mean sizes after three measurements. This SD was the smallest for water control, where particle mean size was also the smallest (around $100 \mathrm{~nm}$ ). The difference between copper SD and Gelsemium SD will help to clarify the meaning of the size measurements. Putting all these aspects of NTA measurements together (numbers, sizes, SDs), we generated a better global view of the results. Particles measured in Cuprum metallicum differed from the particles in Gelsemium. Simple dilutions of Cuprum and Gelsemium can only be discriminated considering the number of particles by frame ( 7 up to 18 times more particles for copper) but not through SDs or mean sizes except for the $10 \mathrm{e}-8$ where the presence of lactose in diluted copper makes the difference. For $\mathrm{cH}$ potentisations, the discrimination between Cuprum and Gelsemium is not in the numbers of particles but clearly through the mean sizes and SDs (almost double in mean size and three times broader SD for copper). For cK potentisations, the $6 \mathrm{ck}$ could not be discriminated with NTA between both HMs but was significant for $30 \mathrm{ck}$ and even more significant for $200 \mathrm{cK}$; the number of particles was five times greater for copper but the mean size of particles was double in Gelsemium.

\section{Lyophilisation Results}

An attempt to visualise particles with SEM-EDS after drying some drops of the solutions failed, and we therefore decided to use a lyophilisation process to remove the water from larger samples by sublimation. After the lyophilisation process of Cuprum metallicum 4cH, lactose was found to agglomerate in very large particles from $75 \mu \mathrm{m}$ up to $740 \mu \mathrm{m}$. To examine this sample, a fresh trituration was required to produce smaller lactose particles. At higher dilutions, these agglomerates did not appear. The free dry residues were

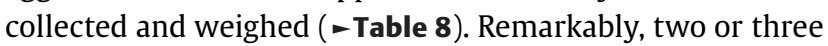
times more material was regularly collected from simply diluted preparations than from potentised samples, even though the number of particles counted by NTA did not suggest this as a generality. For Cuprum $30 \mathrm{cH}$, the number of particles (NTA) was comparable with Gelsemium $30 \mathrm{cH}$, the mean size of particle in Cuprum was double than in Gelsemium, but only $1 \mu \mathrm{g} / \mathrm{g}$ was collected in Cuprum (36 times lower than for Gelsemium $30 \mathrm{cH}$ ). For Cuprum $4 \mathrm{cH}$, the predicted quantity of dry material was collected almost in its entirety. Dry material was collected also from the highest dilutions/potentisations.

Using a tray lyophilisator instead of a single glass round flask lyophilisator, we saw significant material losses; for Gelsemium $200 \mathrm{cK}$, we obtained only $5 \mu \mathrm{g} / \mathrm{g}$ instead of $30.5 \mu \mathrm{g} / \mathrm{g}$; some of the particles adhered to the cover and there was also a risk of cross-contamination.

Deionised water lyophilisation does not produce any measurable quantity of dry material as predicted by DLS even if HPLC-UV could detect some impurities.

At this stage of the research programme, we added more controls to discover whether the collected material was substance specific or was an artefact of the system. Argentum metallicum, Silicea and soluble Kalium muriaticum were 


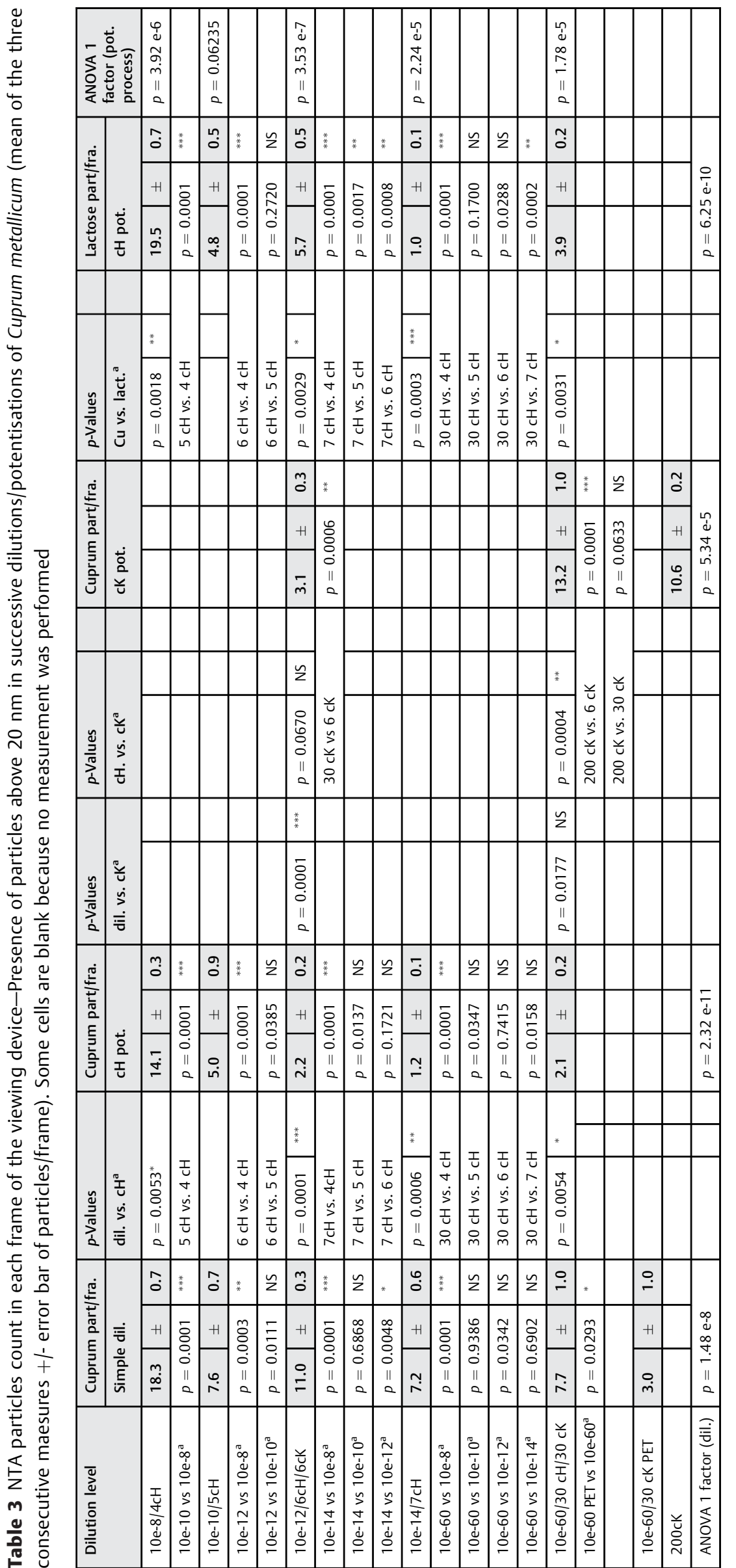




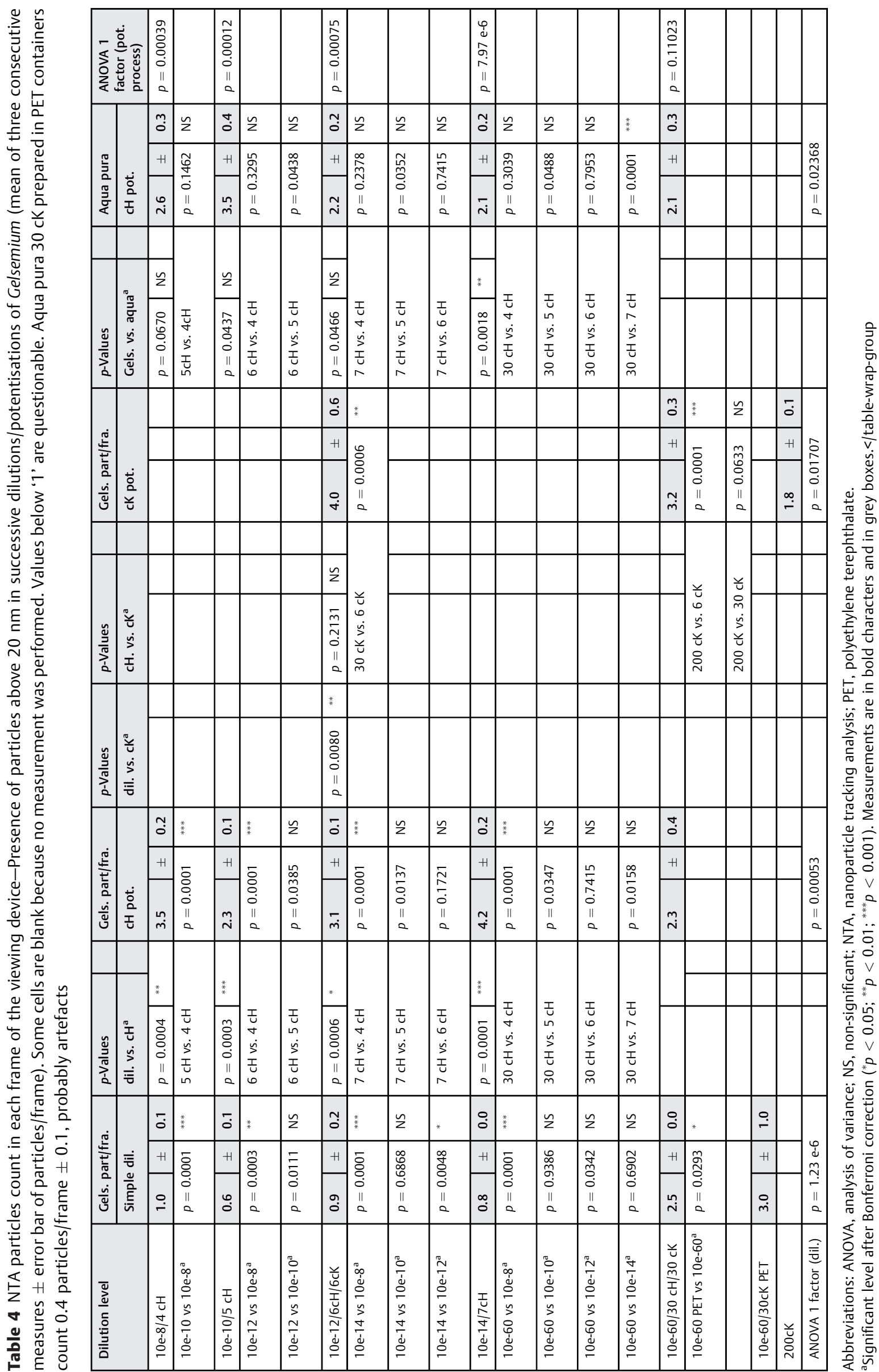



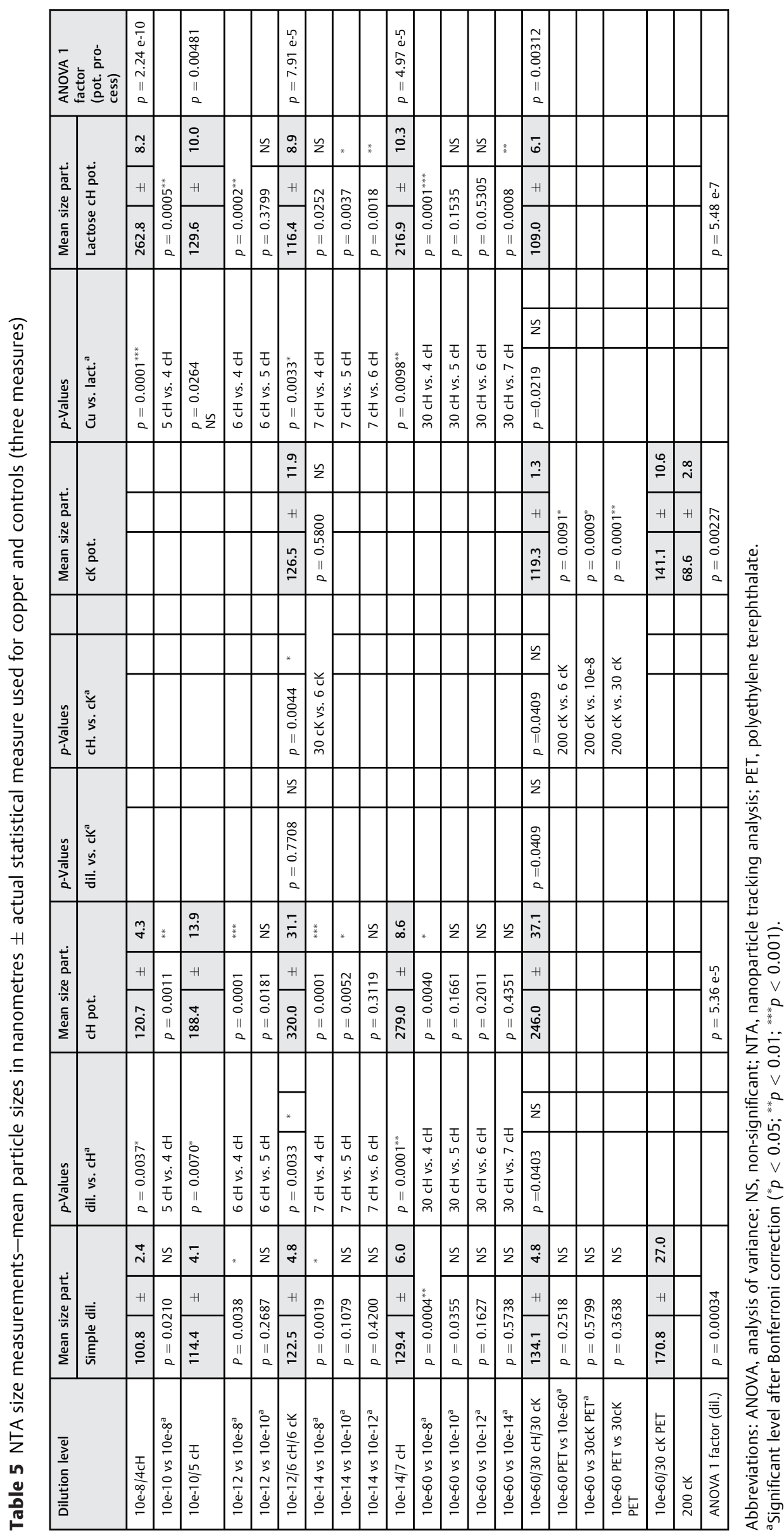


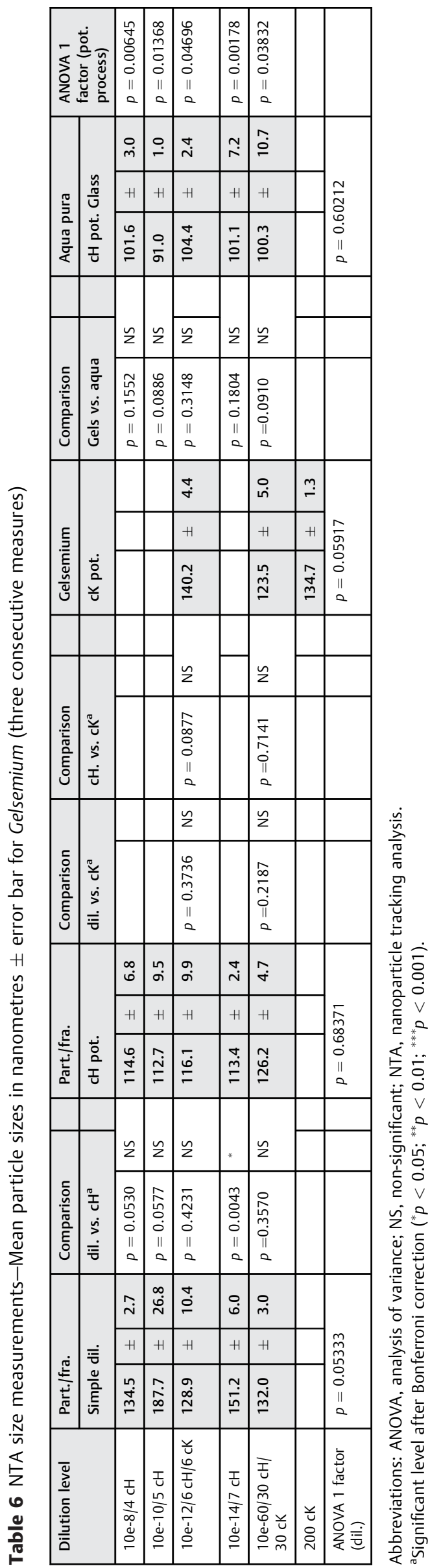

prepared: in $30 \mathrm{cH}, 200 \mathrm{cK}$ and $10 \mathrm{e}-60$ for the first two and 30 $\mathrm{cH}$ only for Kali-mur. There were large differences in the amounts of material collected, depending on which dilution/ potentisation process was used but also depending on the different soluble or insoluble stocks used (-Table 8). The soluble plant extract (Gelsemium) gave the largest quantity of material. Compared to other metals, copper used as the starting substance gave the smallest amount of residual dry material (10 times lower than in Argentum metallicum and Silicea).

\section{Scanning Electron Microscopy with Energy Dispersive X-Ray Spectroscopy}

The lyophilised dry material obtained was visualised by SEM-EDS, producing remarkable images, which gave a detailed picture of the nature of this material. Comparing the appearance of the material, it is possible to differentiate the shapes derived not only from a metal, a salt or a plant but also from different metals and from different dilution/potentisation processes (-Figs. 3-8, see also - Supplementary Figs. 9-19, available online only).

Statistics are here not available because only one measurement was performed (sometimes two). A triple measurement (three zones) of Gelsemium $30 \mathrm{cH}$ material did not show significant differences between these three measurements. The chemistry of these materials determined by EDS shows that they are mostly not composed of the original molecular compounds from the MT. For example, copper, silver or nitrogen could not be identified (-Tables 9-10; -Supplementary Figs. 20-23 [available online only]). In Cuprum $4 \mathrm{cH}$, only carbon and oxygen (lactose) were identified, but in such high concentrations that no other elements could be identified. Nevertheless, as expected from NTA results, there was a specific chemical profile for each of the samples, stocks and/or dilution/dynamisations. As for NTA, to globally observe this phenomenon, we have to integrate the measured percentage of each atom, its mass and the quantity of collected material ( $\mathbf{- T a b l e ~} \mathbf{1 0})$.

\section{Discussion}

\section{Water and/or Alcoholic Solvent}

Following the European pharmacopoeia, ${ }^{12}$ to avoid precipitates, first dilutions of soluble MT must be prepared using the same alcohol concentration as the MT, but alcohol is not required for higher dilutions when producing homeopathic medicines. When a homeopathic medicine is made for bulk storage in a pharmacy, $62 \% \mathrm{w} / \mathrm{w}$ alcohol is added as a preservative, but intermediate dilutions are always prepared in pure water and then discarded. All Korsakov intermediate preparations are similarly prepared using pure water, and alcohol is added only for the final dynamisations. The homeopathic manufacturing tradition expects that the homeopathic information is carried by the water and not by the alcohol.

\section{Nanoparticle Tracking Analysis Conclusions}

Particles were present even in the highest dilutions, in low quantities but clearly measurable. There was a clear 


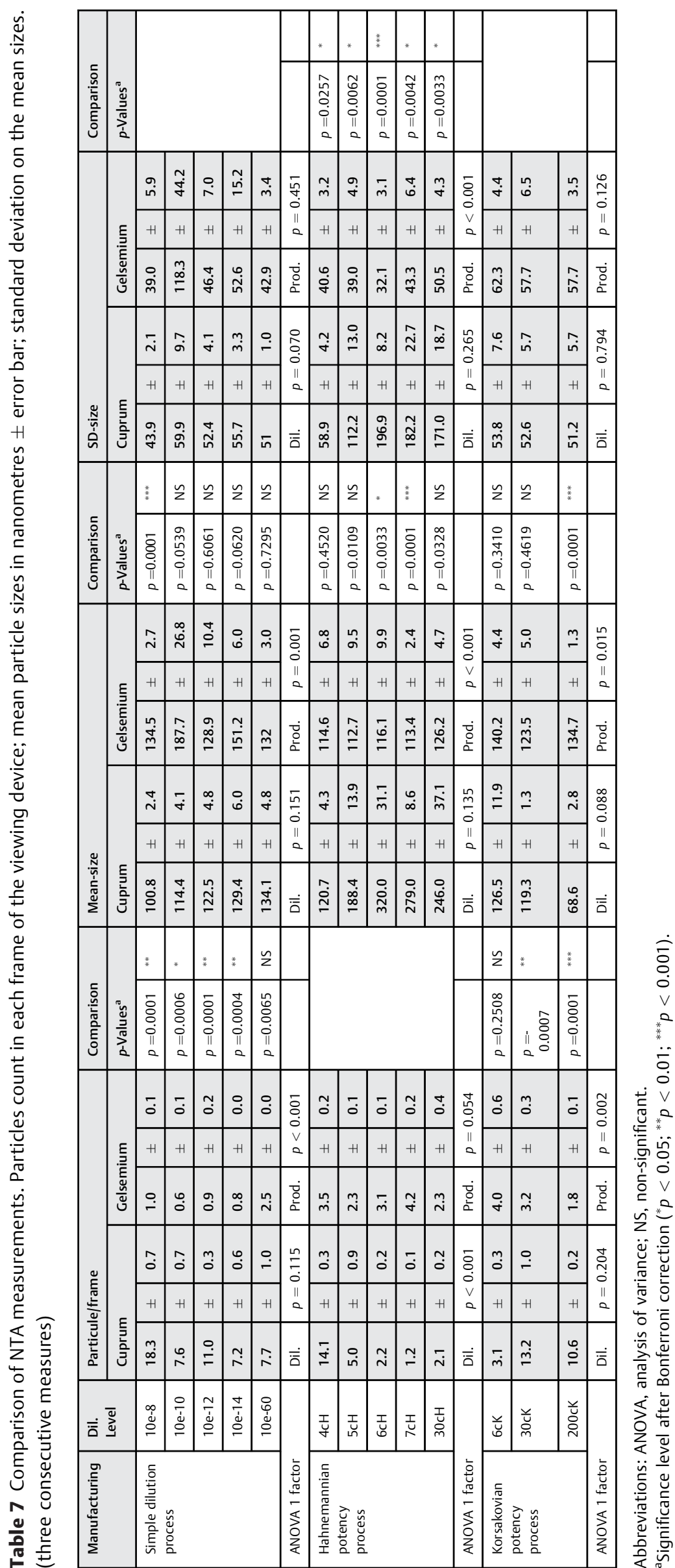


Table 8 Quantifying material after lyophilization. Stock and lactose columns are the theoretically expected quantities. Real measured quantities are in bold. $\mathrm{dH}$ potentisations of Gelsemium were not lyophilisated but measured by HPLC and corresponded to the theory. At each handling of material, a theoretical mathematic uncertainty ${ }^{45}$ must be taken into account: it can be more or less at each step, the same possible error in measurement being the same at each step of the manufacturing process. It would be a concern for high dilutions only. From $5 \mathrm{cH}$, taking a theoretically linear dilution process, it could be possible to find nothing (negative risk), but the fact that measured quantities of dry material exist contradicts this possibility

\begin{tabular}{|c|c|c|c|c|}
\hline & Uncertainty/g* & Stock/g & Lactose/g & Dry material/g \\
\hline Copper & & $999.990 \mu \mathrm{g}$ & 0 & \\
\hline Cupr. met. $1 \mathrm{cH}$ & $\pm 3 \times 10 \mathrm{e}-9$ & $10.000 \mu \mathrm{g}$ & $990.000 \mu \mathrm{g}$ & \\
\hline Cupr. met. $2 \mathrm{cH}$ & $\pm 3 \times 10 \mathrm{e}-9$ & $\pm 100 \mu \mathrm{g}$ & $\pm 999.900 \mu \mathrm{g}$ & \\
\hline Cupr. met. $3 \mathrm{cH}$ & $\pm 3 \times 10 \mathrm{e}-9$ & $\pm 1 \mu \mathrm{g}$ & $\pm 999.999 \mu \mathrm{g}$ & \\
\hline Cupr. met. $4 \mathrm{cH}$ & $\pm 3 \times 10 \mathrm{e}-9$ & In theory $\pm 0.01 \mu \mathrm{g}$ & $\pm 9.999 .99 \mu \mathrm{g}$ & $9.500 .0 \mu \mathrm{g}$ \\
\hline Cupr. met. $30 \mathrm{cH}$ & $\pm 3 \times 10 \mathrm{e}-9$ & In theory $\pm 10 \mathrm{e}-54 \mu \mathrm{g}$ & $\pm 10 \mathrm{e}-48 \mu \mathrm{g}$ & $1.0 \mu \mathrm{g}$ \\
\hline Cupr. met. 200 cK & $\pm 3 \times 10 \mathrm{e}-9$ & In theory $\pm 10 \mathrm{e}-396 \mu \mathrm{g}$ & $\pm 10 \mathrm{e}-388 \mu \mathrm{g}$ & $2.5 \mu \mathrm{g}$ \\
\hline $\begin{array}{l}\text { Cupr. met. diluted } \\
10 \mathrm{e}-60\end{array}$ & $\pm 3 \times 10 \mathrm{e}-9$ & In theory $\pm 10 \mathrm{e}-54 \mathrm{\mu g}$ & $\pm 10 \mathrm{e}-48 \mu \mathrm{g}$ & $3.0 \mu \mathrm{g}$ \\
\hline Cupr. met. $30 \mathrm{cH}$ PET & $\pm 3 \times 10 \mathrm{e}-9$ & In theory $\pm 10 \mathrm{e}-54 \mu \mathrm{g}$ & $\pm 10 \mathrm{e}-48 \mu \mathrm{g}$ & $1.5 \mu \mathrm{g}$ \\
\hline Aqua pura & $\pm 3 \times 10 \mathrm{e}-9$ & In theory 0 & 0 & $0 \mu g$ \\
\hline Aqua pura $30 \mathrm{cH}$ & $\pm 3 \times 10 \mathrm{e}-9$ & In theory 0 & 0 & $2.0 \mu g$ \\
\hline Arg. met. $30 \mathrm{cH}$ & $\pm 3 \times 10 \mathrm{e}-9$ & In theory $\pm 10 \mathrm{e}-54 \mu \mathrm{g}$ & $\pm 10 \mathrm{e}-48 \mu \mathrm{g}$ & $10.0 \mu \mathrm{g}$ \\
\hline Arg. met. $200 \mathrm{cK}$ & $\pm 3 \times 10 \mathrm{e}-9$ & In theory $\pm 10 \mathrm{e}-396 \mu \mathrm{g}$ & $\pm 10 \mathrm{e}-388 \mu \mathrm{g}$ & $7.0 \mu \mathrm{g}$ \\
\hline Arg. met. $10 \mathrm{e}-60$ & $\pm 3 \times 10 \mathrm{e}-9$ & In theory $\pm 10 \mathrm{e}-54 \mathrm{\mu g}$ & $\pm 10 \mathrm{e}-48 \mu \mathrm{g}$ & $20.0 \mu \mathrm{g}$ \\
\hline Silicea $30 \mathrm{cH}$ & $\pm 3 \times 10 \mathrm{e}-9$ & In theory $\pm 10 \mathrm{e}-54 \mu \mathrm{g}$ & $\pm 10 \mathrm{e}-48 \mu \mathrm{g}$ & $12.0 \mu \mathrm{g}$ \\
\hline Silicea $200 \mathrm{cK}$ & $\pm 3 \times 10 \mathrm{e}-9$ & In theory $\pm 10 \mathrm{e}-396 \mu \mathrm{g}$ & $\pm 10 \mathrm{e}-388 \mu \mathrm{g}$ & $8.0 \mu \mathrm{g}$ \\
\hline Silicea 10e-60 & $\pm 3 \times 10 \mathrm{e}-9$ & In theory $\pm 10 \mathrm{e}-54 \mu \mathrm{g}$ & $\pm 10 \mathrm{e}-48 \mu \mathrm{g}$ & $19.0 \mu \mathrm{g}$ \\
\hline Kali.mur. $30 \mathrm{cH}$ & $\pm 3 \times 10 \mathrm{e}-9$ & In theory $\pm 10 \mathrm{e}-54 \mu \mathrm{g}$ & 0 & $17.0 \mu g$ \\
\hline Gelsemium & & Gelsemine/g & & \\
\hline $4 \mathrm{cH}$ & $\pm 3 \times 10 \mathrm{e}-9$ & In theory $\pm 0.01 \mu \mathrm{g}$ & & $42 \mu \mathrm{g}$ \\
\hline $30 \mathrm{cH}$ & $\pm 3 \times 10 \mathrm{e}-9$ & In theory $\pm 10 \mathrm{e}-54 \mu \mathrm{g}$ & & $36 \mu \mathrm{g}$ \\
\hline $200 \mathrm{cK}$ & $\pm 3 \times 10 \mathrm{e}-9$ & In theory $\pm 10 \mathrm{e}-396 \mu \mathrm{g}$ & & $30.5 \mu \mathrm{g}$ \\
\hline Diluted $10 \mathrm{e}-60$ & $\pm 3 \times 10 \mathrm{e}-9$ & In theory $\pm 10 \mathrm{e}-54 \mathrm{\mu g}$ & & $71 \mu \mathrm{g}$ \\
\hline
\end{tabular}

Abbreviations: HPLC, high-performance liquid chromatography; PET, polyethylene terephthalate.

difference in all NTA aspects from the potentised water control, prepared in PET containers, which contained only a few particles of a large size distribution. This PET water control was below the limit of the NTA methodology ( $>1$ particle per frame); this value (0.4) was lower than in the Gelsemium simple dilution series (the lowest for numbers of particles by frame) and is questionable.

\section{Material composition of Homeopathic Medicines}

The idea that homeopathic medicines are non-material, propounded by both opponents of homeopathy and by traditional homeopathic practitioners, cannot be maintained in view of these findings. Science is measurement; measurements are facts that cannot be denied. Nevertheless, the presence of these few particles does not allow us to conclude that the effect of homeopathy is due to a classical moleculereceptor interaction. Given that the final product (impreg- nated pills, globules, granules etc.) contains only a very small quantity of the HMs in question, a different pathway is much more likely. To verify this assertion, other methodologies, such as $\mathrm{NMR}^{15}$ and/or electro-photonic analysis, are required. It is notable that the mean particle sizes measured by NTA (between 100 and $170 \mathrm{~nm}$ ) are consistent with the size predictions of quantum coherence domains generated during the potentisation process. ${ }^{41}$

\section{Nanobubbles versus NPs}

It is important to recognise that there is a large difference between the quantities of lyophilised dry material obtained in the Gelsemium preparations and the Cuprum control samples, even though the particle count with NTA did not predict this (comparable quantities of particle counts). The hypothesis that nanobubbles generated during the trituration process ${ }^{3}$ are disappearing during the lyophilisation 


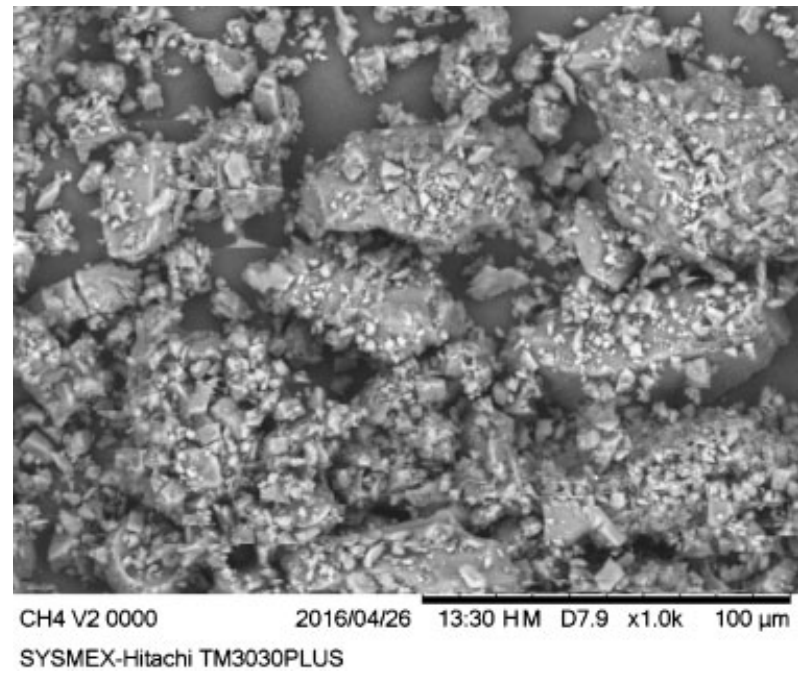

Fig. 3 Cuprum metallicum $4 \mathrm{cH}$ originally magnified $\times 1000$. A mixture of fine and larger grit cubical structures of different densities is seen.

process is plausible. Indeed, for insoluble material such as metals (e.g. copper), the first dynamisations occur by trituration in sugar, which could generate more nanobubbles than when no trituration is needed. NTA cannot discriminate nanobubbles from other NPs. This hypothesis requires verification in the future.

\section{Manufacturing Conditions}

During all these measurements, all manufacturing variables were fully controlled: same environment, same water, same alcohol, same glass, same machines, same stock, same staff for each step of manufacture and measurement. Whilst such precautions strengthen the results, these can be generalised only with care; many different homeopathic medicines exist in various concentrations. In the future, it will be possible to

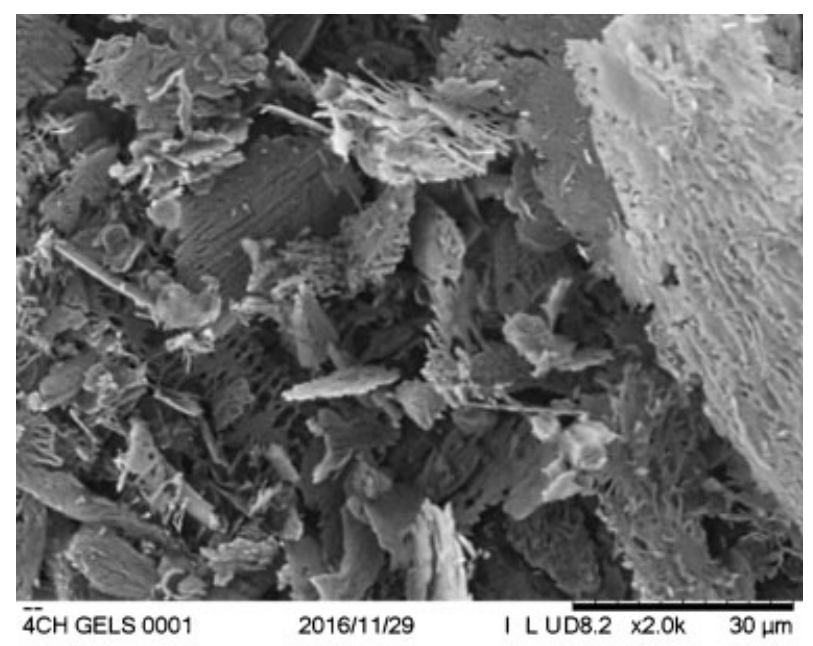

SYSMEX-Hitachi TM3030PLUS

Fig. 4 Gelsemium sempervirens $4 \mathrm{cH}$ originally magnified $\times 2000$. Finely carved structures are seen, differing in size but of very homogeneous density.

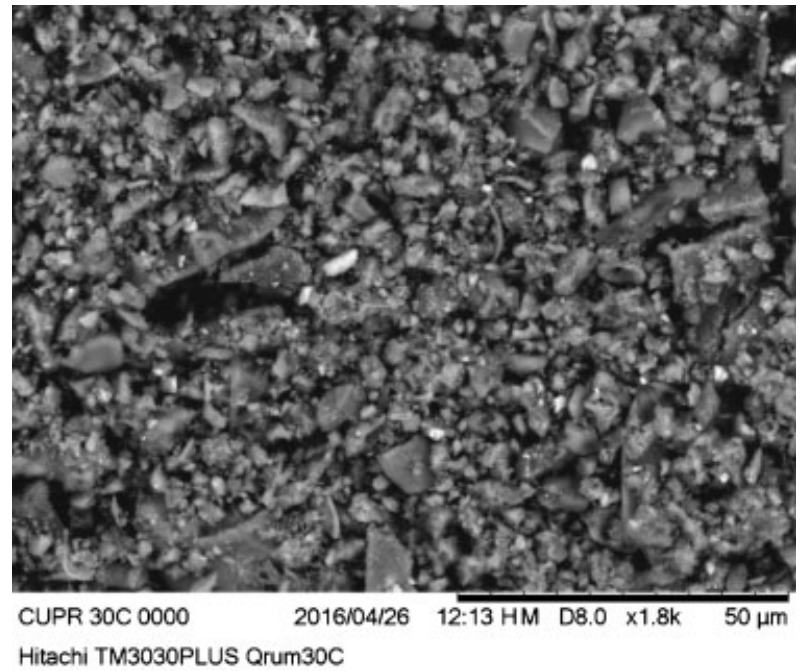

Fig. 5 Cuprum $30 \mathrm{cH}$ originally magnified $\times 1800$. A mixture of grit and very small 'cauliflowers' is seen, a kind of crushed mix of the image obtained for $4 \mathrm{cH}$ and $30 \mathrm{cH}$ in polyethylene terephthalate containers (see supplementary figures).

study the impact of changing certain parameters, such as the use of different types of glass container and the number of dynamisations.

All measurements were carried out using samples prepared without alcohol. We did the same for the measurements of NMR relaxation times ${ }^{15}$ that also require preparations made with pure water. However, with electro-photonic analysis, it is possible to use commercial homeopathic medicines prepared with a mix of water and alcohol. Some may argue that alcohol is needed for the homeopathic reaction; this aspect needs further investigation.

\section{A Homeopathic Medicine Is a Complex System}

Nanoparticle tracking analysis (count and mean sizes of particles) alone does not permit the discrimination of water

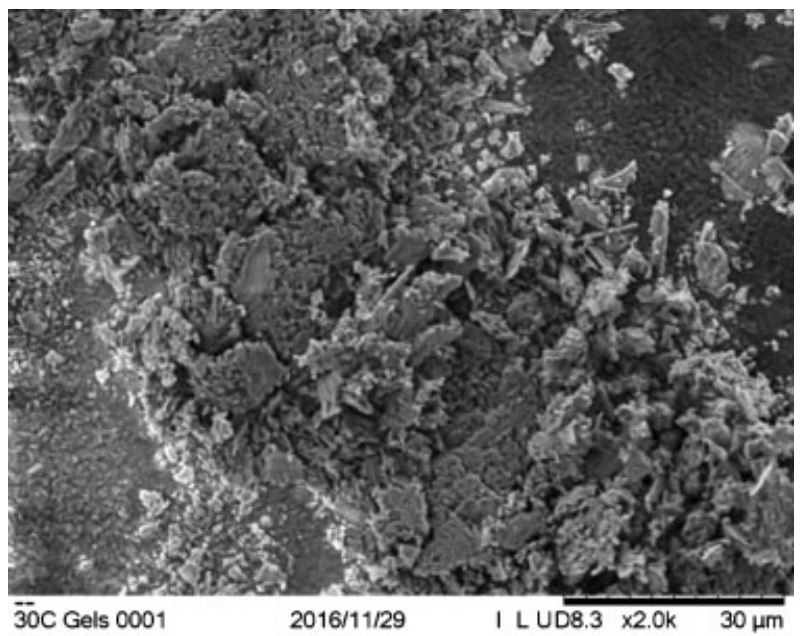

SYSMEX-Hitachi TM3030PLUS

Fig. 6 Gelsemium $30 \mathrm{cH}$ originally magnified $\times 2000$. Carved structures are seen as in $4 \mathrm{cH}$ but smaller in size and of very homogeneous density. 


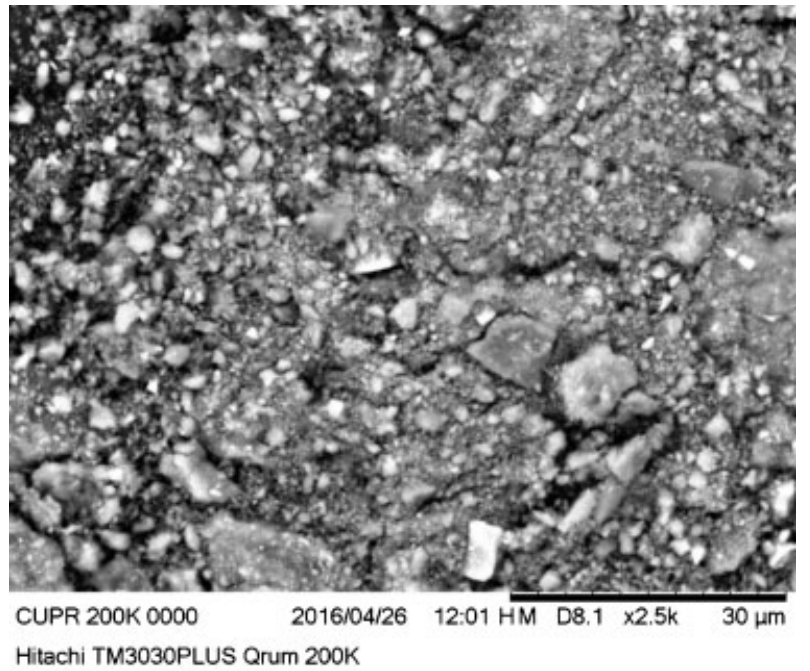

Fig. 7 Cuprum 200 cK originally magnified $\times 2500$. Small chunks embedded in a small, variably-sized sand structure; the particles are significantly smaller than in $30 \mathrm{cH}$.

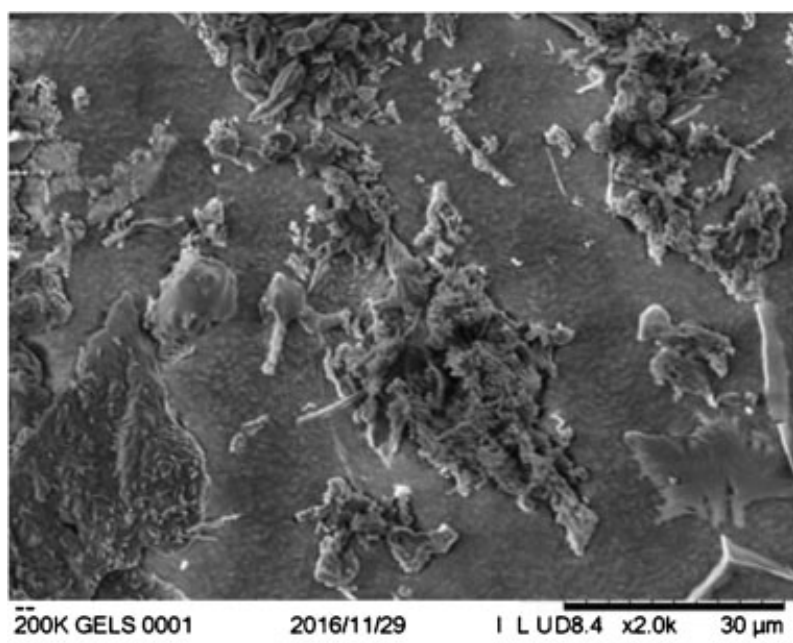

SYSMEX-Hitachi TM3030PLUS

Fig. 8 Gelsemium sempervirens 200 cK originally magnified $\times 2000$. Carved structures are seen as in $4 \mathrm{cH}$ and $30 \mathrm{cH}$, of homogeneous density but regrouped together in small amounts.

controls and $\mathrm{cH}$ potentisations of Gelsemium; this only becomes possible by combining all the results. The great variation in the size of particles ( - Table 7 ) is an indication of the complex shapes of particles in homeopathic medicines.
Water controls have the narrowest size distribution curves (-Supplementary Fig. 8, available online only). There is also a plausible presence of nanobubbles in triturated HMs. In a future article, we intend to discuss all these findings in the context of the wider literature, adding the new NMR results. ${ }^{15}$ We are aware that these findings are somewhat startling, illustrating the impossibility of detecting any major elements from the original stock (copper, silver, gelsemine, etc.) and showing that the remedy specificity derives not from a single element but from very small, complex particles.

\section{Origin of the Measured Material in PET Containers}

The number of particles by frame (NTA) in Cuprum $30 \mathrm{cH}$ prepared in PET containers is significantly higher than in dynamised water in PET containers (75\% higher). What is the origin of these particles? For a same manufacturing process, this difference can only derive from the material $(3 \mathrm{cH}$ triturated Cuprum) added to the water for further dynamisations.

\section{Origin of the Measured Material in HMs}

The specificities of each preparation (different starting material, specific manufacturing process, level of dilution/dynamisation) are identified. The common factors to all preparations are also known: containers, passivation process, measurement techniques, quality of water and ambient air.

Soda glass containers are leaching particles; surely more than a PET container (see potentised water manufacturing line in soda glass versus PET, - Table 8). Ambient air mix may play a role considering lactose, used for the trituration. In pharmaceutical-grade lactose monohydrate, some heavy metals are tolerated $(\mathrm{Pb} \leq 0.5 \mathrm{ppm}$, As $\leq 5 \mathrm{ppm}$, Cd $\leq 1 \mathrm{ppm}, \mathrm{Hg} \leq 5 \mathrm{ppm}$ ) and non-toxic elements may not exceed $2 \%$ (glucose and other impurities). It must be noted that none of these elements was identified in the collected dry material. For Cuprum, the first dilution after trituration will certainly contain lactose but copper will already be detectable with only a high level of uncertainty ( - Table 8). As such, the presence of carbon and oxygen is expected (from the lactose), but the oxygen is in a higher proportion than would be expected from lactose. This can be explained by the trituration process. The other elements may partially originate from the triturated lactose, air contaminants, water contaminants and containers but their percentages and especially their variability question this line of argument. PET containers may leach but the quantities of material are non-significant (see dynamised water in PET).

Table 9 Atom percentages detected in some of the preparations

\begin{tabular}{|l|l|l|l|l|l|l|l|l|l|l|l|l|}
\hline & $\mathrm{C} \%$ & $\mathbf{O} \%$ & $\mathrm{Na} \%$ & $\mathrm{Mg} \%$ & $\mathrm{Al} \%$ & $\mathrm{Si} \%$ & $\mathrm{~S} \%$ & $\mathrm{Cl} \%$ & $\mathrm{~K} \%$ & $\mathrm{Ca} \%$ & $\mathrm{P} \%$ & $\mathrm{Ti} \%$ \\
\hline Cuprum 30 cH & 10.42 & 42.66 & 22.29 & 0.95 & 0.54 & 9.86 & 0.73 & 1.26 & 2.26 & 8.49 & 0.14 & 0.38 \\
\hline Cuprum 30 cH PET & 18.89 & 50.46 & 26.13 & 1.09 & 0.42 & 1.21 & 0.36 & 1.51 & 0.57 & 0.45 & 0 & 0 \\
\hline Aqua 30 cH & 10.69 & 43.25 & 22.66 & 1.58 & 0.36 & 12,4 & 0.37 & 0.55 & 1.75 & 6.39 & 0 & 0 \\
\hline Gelsemium 30 cH & 36.12 & 41.91 & 17.58 & 0 & 0.85 & 1.42 & 1.15 & 0.42 & 0.55 & 0 & 0 & 0 \\
\hline
\end{tabular}

Abbreviation: PET, polyethylene terephthalate. 


\begin{tabular}{|c|c|c|c|c|c|c|c|c|c|c|c|c|c|}
\hline$\frac{\sim}{\varrho}$ & $\begin{array}{l}0 \\
\dot{d} \\
\dot{d} \\
\stackrel{0}{0}\end{array}$ & $\mid \begin{array}{l}\stackrel{d}{N} \\
\stackrel{\sim}{N}\end{array}$ & $\begin{array}{l}\infty \\
\infty \\
\dot{p} \\
\end{array}$ & $\begin{array}{l}0 \\
\stackrel{1}{ } \\
\dot{\tilde{D}} \\
i n\end{array}$ & $\begin{array}{l}0 \\
m \\
0 \\
0 \\
0\end{array}$ & $\underset{\stackrel{N}{E}}{\stackrel{N}{E}}$ & 0 & $\begin{array}{l}0 \\
\tilde{r} \\
\dot{f}\end{array}$ & $\mid \begin{array}{l}n \\
\hat{n} \\
\grave{n}\end{array}$ & $\mid \begin{array}{l}\tilde{b} \\
\stackrel{\sim}{\sim}\end{array}$ & 0 & 0 & 0 \\
\hline$\frac{n}{\Xi}$ & $\begin{array}{l}\text { ¿ } \\
\text { ¿ } \\
\text {. }\end{array}$ & $\mid \begin{array}{c}\infty \\
\infty \\
0 \\
\infty \\
m \\
m\end{array}$ & 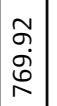 & $\begin{array}{l}g \\
\infty \\
\infty \\
m\end{array}$ & $\begin{array}{c}\hat{N} \\
\tilde{N} \\
\sigma\end{array}$ & مै & $\begin{array}{l}\stackrel{\infty}{ } \\
\tilde{m} \\
\tilde{\sim} \\
\sim\end{array}$ & 0 & $\mid \begin{array}{l}\stackrel{0}{1} \\
\stackrel{0}{\circ}\end{array}$ & $\mid \begin{array}{l}\stackrel{q}{q} \\
\dot{\sim}\end{array}$ & 10 & 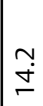 & 0 \\
\hline$\frac{n}{v}$ & $\begin{array}{l}I \\
\text { I } \\
\text { D }\end{array}$ & $\mid \begin{array}{l}0 \\
0 \\
\circ \\
\sim\end{array}$ & $\mid \begin{array}{l}\stackrel{g}{g} \\
\dot{J} \\
\sim\end{array}$ & 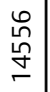 & $\overline{\tilde{q}}$ & 0 & 0 & $\stackrel{\stackrel{\sim}{\sim}}{\stackrel{m}{\sim}}$ & $\mid \begin{array}{c}\sim \\
\grave{\nu} \\
\infty\end{array}$ & $\mid \begin{array}{c}\mathfrak{N} \\
\underset{N}{N}\end{array}$ & 0 & \begin{tabular}{|l}
$\infty$ \\
$\dot{0}$ \\
$\tilde{n}$
\end{tabular} & 0 \\
\hline$\frac{\breve{n}}{\Xi}$ & \begin{tabular}{|l}
$T$ \\
J
\end{tabular} & 离 & $\begin{array}{l}\hat{\sigma} \\
\tilde{N}\end{array}$ & $\begin{array}{l}\stackrel{g}{i} \\
\stackrel{n}{n}\end{array}$ & $\begin{array}{l}\infty \\
\infty \\
\stackrel{0}{ }\end{array}$ & \begin{tabular}{|l} 
f \\
$\dot{f}$
\end{tabular} & 0 & 0 & 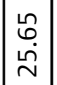 & $\begin{array}{l}\infty \\
\stackrel{\dot{d}}{\sim}\end{array}$ & $\mid \begin{array}{c}\sim \\
\dot{D} \\
\stackrel{D}{\sim}\end{array}$ & o & 0 \\
\hline \begin{tabular}{|l}
$\frac{E}{\underline{\underline{I}}}$ \\
$\underline{\underline{\underline{\underline{m}}}}$
\end{tabular} & $\begin{array}{l}I \\
I \\
0 \\
\text { D }\end{array}$ & $\begin{array}{c}\overline{\dot{d}} \\
\dot{\mathscr{\sigma}}\end{array}$ & $\mid \begin{array}{c}\stackrel{+}{\sim} \\
\dot{D} \\
\infty\end{array}$ & $\begin{array}{l}6 \\
\dot{2} \\
\stackrel{N}{N}\end{array}$ & $\begin{array}{l}\hat{\dot{b}} \\
\tilde{m} \\
\dot{m}\end{array}$ & 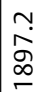 & $\left|\begin{array}{l}\infty \\
\dot{0} \\
\dot{m} \\
m\end{array}\right|$ & $\mid \begin{array}{l}m \\
\stackrel{n}{0} \\
\underline{0}\end{array}$ & 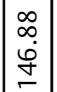 & $\mid \begin{array}{l}0 \\
2 \\
\dot{j} \\
m\end{array}$ & 0 & 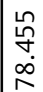 & 0 \\
\hline$\overline{\bar{n}}$ & 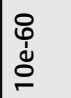 & $\left|\begin{array}{c}0 \\
\dot{\dot{d}} \\
\dot{\infty} \\
\bar{m}\end{array}\right|$ & 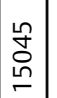 & $\begin{array}{l}\stackrel{\sim}{n} \\
\dot{v} \\
\tilde{y}\end{array}$ & \begin{tabular}{l}
$\infty$ \\
$\check{\Omega}$ \\
\hdashline
\end{tabular} & 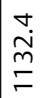 & 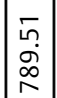 & 0 & $\mid \begin{array}{l}0 \\
\dot{0} \\
0\end{array}$ & 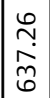 & $\left|\begin{array}{l}0 \\
0 \\
\omega \\
\\
n\end{array}\right|$ & $\mid \begin{array}{l}0 \\
\stackrel{\infty}{\infty} \\
\stackrel{\sim}{\simeq}\end{array}$ & 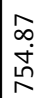 \\
\hline$\overline{\bar{n}}$ & 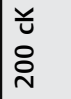 & $\left|\begin{array}{l}\mathfrak{g} \\
\hat{L} \\
\stackrel{D}{N}\end{array}\right|$ & $\left|\begin{array}{l}0 \\
\infty \\
\infty \\
\infty \\
n\end{array}\right|$ & $\begin{array}{l}m \\
\dot{a} \\
\infty \\
m\end{array}$ & $\begin{array}{l}\vec{b} \\
0 \\
0 \\
\infty \\
\infty\end{array}$ & d & $\mid \begin{array}{c}\stackrel{J}{\sim} \\
\dot{D} \\
\sim\end{array}$ & 8 & 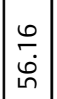 & \begin{tabular}{|l}
$\infty$ \\
$\stackrel{\infty}{\simeq}$ \\
$\dot{ \pm}$
\end{tabular} & 0 & $\begin{array}{l}\stackrel{2}{2} \\
\text { గn }\end{array}$ & 0 \\
\hline$\overline{\bar{n}}$ & 蒿 & $\mid \begin{array}{c}\hat{\sim} \\
\tilde{\sim}\end{array}$ & $\mid \begin{array}{l}\stackrel{\sim}{N} \\
\hat{\sigma}\end{array}$ & $\begin{array}{c}\hat{n} \\
\stackrel{\operatorname{q}}{y}\end{array}$ & $\begin{array}{l}\bar{\zeta} \\
上\end{array}$ & 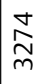 & 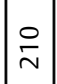 & $\begin{array}{l}0 \\
0 \\
\sigma \\
\sigma\end{array}$ & $\mid \begin{array}{l}\infty \\
\dot{q} \\
\dot{g} \\
\end{array}$ & 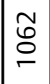 & 0 & 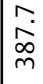 & 0 \\
\hline 荌 & 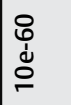 & 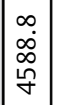 & $\begin{array}{l}\tilde{n} \\
\hat{0} \\
0 \\
0\end{array}$ & $\begin{array}{l}\infty \\
\tilde{m} \\
0 \\
\mathscr{b}\end{array}$ & $\begin{array}{l}\varphi \\
\dot{1} \\
\infty \\
\infty \\
\dot{m}\end{array}$ & $\underset{\text { Nे }}{\tilde{m}}$ & $\mid \begin{array}{l}\infty \\
\stackrel{n}{n} \\
\tilde{q} \\
\dot{q}\end{array}$ & 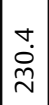 & $\stackrel{+}{\stackrel{\sim}{\sim}}$ & \begin{tabular}{|l|}
$\infty$ \\
$\infty$ \\
$\stackrel{+}{\Gamma}$ \\
\end{tabular} & 0 & $\frac{m}{n}$ & 0 \\
\hline$\frac{\pi}{\alpha}$ & $\begin{array}{l}\text { ¿ } \\
\stackrel{\text { N }}{2}\end{array}$ & $\mid \begin{array}{l}\text { 足 } \\
\stackrel{0}{\circ}\end{array}$ & $\mid \begin{array}{l} \pm \\
\tilde{n} \\
n\end{array}$ & 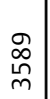 & $\begin{array}{l}\stackrel{\bullet}{0} \\
\stackrel{\sim}{\simeq}\end{array}$ & $\mid \begin{array}{c}n \\
\frac{0}{m}\end{array}$ & 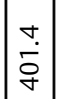 & $\begin{array}{l}\infty \\
\dot{0} \\
0\end{array}$ & $\left|\begin{array}{c}\tilde{D} \\
\dot{m} \\
\dot{m}\end{array}\right|$ & $\begin{array}{c}\dot{J} \\
\dot{\sigma} \\
\dot{\sigma}\end{array}$ & 0 & $\begin{array}{l}\stackrel{m}{+} \\
\stackrel{\sigma}{*}\end{array}$ & 0 \\
\hline 定 & 壳 & 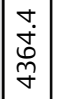 & 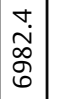 & $\begin{array}{l}0 \\
\dot{0} \\
\stackrel{1}{m}\end{array}$ & 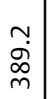 & $\stackrel{\stackrel{g}{N}}{\sim}$ & $\mid \begin{array}{c}\tilde{L} \\
\dot{\infty} \\
\infty\end{array}$ & $\begin{array}{l}\stackrel{N}{*} \\
\dot{f}\end{array}$ & \begin{tabular}{l|}
$\infty$ \\
$\dot{b}$ \\
$\dot{b}$
\end{tabular} & $\begin{array}{l}\dot{\sigma} \\
\dot{\sigma} \\
+\end{array}$ & 0 & कृ. & 0 \\
\hline 亏气 & $\begin{array}{l}I \\
\bar{L} \\
\dot{m}\end{array}$ & $\begin{array}{c}v \\
\tilde{0} \\
\dot{j} \\
m\end{array}$ & 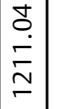 & $\begin{array}{l}\llcorner \\
\stackrel{\infty}{+} \\
\dot{5} \\
8\end{array}$ & $\begin{array}{l}\text { D } \\
\infty \\
\dot{0} \\
\text { மn }\end{array}$ & $\lesssim$ & $\mid \begin{array}{l}n \\
\stackrel{n}{r} \\
\hat{n} \\
\hat{m}\end{array}$ & $\stackrel{\infty}{\stackrel{\infty}{\sim}}$ & $\begin{array}{l}\tilde{丶} \\
\stackrel{\Gamma}{二}\end{array}$ & $\mid \begin{array}{l}\stackrel{q}{p} \\
m \\
m \\
m\end{array}$ & 0 & 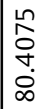 & 0 \\
\hline 亨 & 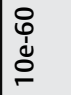 & $\mid \begin{array}{l}\swarrow \\
\tilde{\sigma} \\
\sigma\end{array}$ & 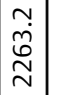 & $\begin{array}{l}\stackrel{m}{\tilde{D}} \\
\stackrel{0}{\sigma}\end{array}$ & $\begin{array}{l}0 \\
0 \\
\infty \\
\infty \\
\sigma \\
\sigma\end{array}$ & 离 & $\mid \begin{array}{l}\bar{\sigma} \\
\sigma \\
g \\
\end{array}$ & 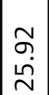 & $\left|\begin{array}{l}\infty \\
\stackrel{0}{0} \\
\dot{m}\end{array}\right|$ & \begin{tabular}{|l|} 
\\
$\infty$ \\
0 \\
0
\end{tabular} & 10 & $\frac{m}{\sim}$ & 0 \\
\hline 产 & $\begin{array}{l}\text { ப } \\
\text { ¿े }\end{array}$ & $\begin{array}{c}\sim \\
\sim \\
\infty \\
o \\
i n\end{array}$ & 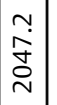 & 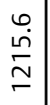 & $\begin{array}{l}\infty \\
\stackrel{\dot{f}}{\tilde{m}}\end{array}$ & $\stackrel{n}{\sim}$ & $\mid \begin{array}{l}\infty \\
\stackrel{0}{0} \\
\stackrel{\sigma}{\sigma} \\
\end{array}$ & $\begin{array}{l}0 \\
\dot{m} \\
\dot{m}\end{array}$ & 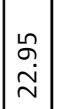 & $\begin{array}{l}n \\
\stackrel{2}{n}\end{array}$ & 0 & $\begin{array}{l}\stackrel{\nu}{\sigma} \\
\hat{\sigma} \\
\dot{f}\end{array}$ & 0 \\
\hline 产 & I & $\mid \begin{array}{c}-\dot{\infty} \\
\stackrel{\infty}{\sigma}\end{array}$ & $\mid \begin{array}{c}\infty \\
\dot{亠} \\
\infty\end{array}$ & 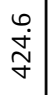 & $\stackrel{\infty}{-}$ & $\frac{7}{6}$ & 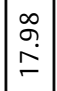 & $\begin{array}{l}\infty \\
0 \\
\dot{+}\end{array}$ & 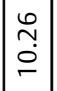 & $\begin{array}{l}\mathscr{g} \\
\dot{F}\end{array}$ & 0 & 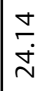 & 0 \\
\hline 亏气 & 昰 & 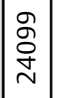 & $\begin{array}{l}\tilde{N} \\
\infty \\
0 \\
0\end{array} \mid$ & $\begin{array}{l}\bar{m} \\
\infty \\
\infty\end{array}$ & $\left|\begin{array}{l}N \\
\hat{D} \\
\hat{N}\end{array}\right|$ & 0 & 0 & 0 & 0 & 10 & 0 & 10 & 0 \\
\hline 吾 & 壳 & $\mid \begin{array}{l}\infty \\
\dot{0} \\
\dot{q}\end{array}$ & $\begin{array}{l}\tilde{\tilde{\omega}} \\
\underline{\sigma}\end{array}$ & 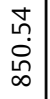 & $\mid \begin{array}{l}\infty \\
0 \\
\dot{0} \\
\hat{q}\end{array}$ & $\underset{\sim}{\tilde{N}}$ & 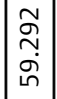 & $\begin{array}{l}\infty \\
0 \\
\dot{+} \\
\end{array}$ & $\mid \begin{array}{l}\stackrel{n}{m} \\
\stackrel{m}{n}\end{array}$ & 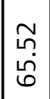 & 0 & $\begin{array}{l}\text { م̂̀ } \\
\text { ָे }\end{array}$ & 0 \\
\hline & & 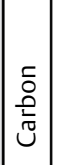 & 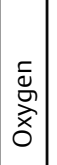 & 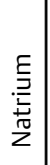 & 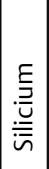 & $\frac{E}{\frac{E}{U}}$ & 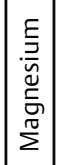 & 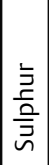 & 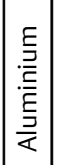 & 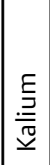 & 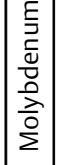 & 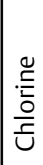 & 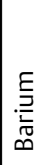 \\
\hline
\end{tabular}

Another origin may be the measurement devices. As example, the concentration is required before elements can be identified using the EDX process. The lyophilisation takes place in a round DURAN flask. For all preparations, $200 \mathrm{cc}$ was used for this step, except for Cuprum PET $30 \mathrm{cH}$ where $1.000 \mathrm{cc}$ was used because we did not expect to collect much material (NTA counting showed fewer particles than in the other preparations.). Using five times more liquid to lyophilisate also means five times longer duration of contact with the lyophilisator flask; this is made of very hard glass of the following composition: $4 \%$ boron, $54 \%$ oxygen, $2.8 \%$ sodium, $1.1 \%$ aluminium, $37.7 \%$ silica and $0.3 \%$ potassium. As such, theoretically, we can expect more particles from the lyophilisation flask than other preparations even if a release of particles, as occurs during preparation in soda glass containers, is not expected at a significant level at this step prior to the EDX measurements because DURAN glass is more stable than any other glass. Comparing the percentages of the different elements in aqua pura $30 \mathrm{cH}$, Cuprum $30 \mathrm{cH}$ (glass containers) and Cuprum $30 \mathrm{cH}$ (PET), we observed about the same percentages of carbon, oxygen, aluminium, sulphur and potassium, whilst for the PET preparations sodium was higher $(26 \%>18.5 \%)$ as was chlorine $(1.5 \%>0.5 \%)$, with lower concentrations of silica $(1.2 \%<7 \%)$, calcium $(0.4 \%<3 \%)$ and magnesium $(0.1 \%<1 \%)$. Proportionally, the largest difference was clearly the amount of silica when pharmaceutical-grade soda glass was used for the preparation of these homeopathic medicines. For aqua pura in soda glass, carbon and oxygen could not derive from lactose but rather must have been introduced during the manufacturing process.

Lastly, a possible factor may be gas contamination from the ambient air $\left(\mathrm{CO}_{2}\right.$, for example) or by hydrophobic dust (such as carbon) which is very difficult to eliminate by washing containers with water before passivation. Ambient air was controlled during the manufacturing process; all operations took place in the same cabin protected by laminar air flow. The lyophilisation process occurred in a closed glass round flask and there was contact with air only when filling and emptying the flask.

The quality of the lactose, the type of glass used and ambient air quality must always be taken into consideration during homeopathic preparations and measurements. These aspects were controlled by a complete standardisation of the manufacturing process and measurement techniques. If all these factors would have to explain the origin of the particles, then we have a problem, because all measurements would be uniform between all samples. We have measured differences in numbers, sizes, distribution of sizes and chemistry of the particles that cannot be explained by all these factors.

Another concern about this hypothesis is that it is only relevant for very low element concentrations $(\leq 1 \mathrm{ppm}$, found only in some copper potencies and in these PET preparations). But it cannot explain the different proportions of elements in higher concentrations found in all other preparations (dynamised or not).

Of course, replication using different and repeated manufacturing lines of similar preparations is needed. This publication is a basis for future verifications of these measurements. Homeopathic medicines are much more complex and elaborated than 
previously expected. The role of the starting material cannot be denied.

\section{Chemistry of the Material}

The SEM-EDX is only semi-quantitative, meaning that if a certain element is present only at a very low concentration compared to other compounds, it will not be identified. The chemistry of the materials, determined by EDS, shows that they are not composed only of molecular compounds from the original MT. We did not find copper or silver in the samples, but nevertheless each of the samples, stocks and/or dilution/ dynamisations has a specific composition, and the proportions of the various atoms resulted in a specific chemical profile. Because of the absence of any particles in the pure deionised water used (NTA), the presence of these elements can only be explained by an interaction between the original stock, the glass containers used, ambient air and the deionised water. Some of them may derive from the stock itself, whilst others could be extracted from the glass due to the glass-aggressive nature of deionised water. The deionised water's aggressiveness could be tempered, more or less, by the addition of the starting material or previous dilution. The step-by-step dilution/dynamisation process plays a significant role because particles are also produced in deionised potentised aqua pura $30 \mathrm{cH}$; in this case, this can only be due to a reaction between the glass and the water. On the other hand, the specificities of the different samples clearly illustrate the persistent impact of the original stock throughout the dilution or potentisation process. A simple dilution is not a potentisation, and there is a difference between the $\mathrm{cH}, \mathrm{cK}$ potentisation processes and controls.

Even though measurements were not all carried out on the same day, fresh standardised preparations (GPP) were used each time, allowing the results to be compared. We had some concern about the quality of a single sample of Silicea 10e-60 because this was the only sample to contain the element barium, a water contaminant; the other samples prepared on the same day were not contaminated. Molybdenum should also be mentioned; this was identified only in Gelsemium $4 \mathrm{cH}$ and is an original component of the MT. ${ }^{42}$ This atom was not found in Gelsemium $30 \mathrm{cH}, 200 \mathrm{cK}$ or $10 \mathrm{e}-60$, which rules out any involvement of the glass containers. Molybdenum is part of the xanthine oxidase enzyme that is found largely in the roots of plants, and further investigations are needed to follow this element through a full range of potentisations. For those stocks that were triturated, the percentage of silica was highest in Silicium $30 \mathrm{cH}$. The control Kalium muriaticum was added because as a soluble stock (no trituration required) any possible effect of lactose was avoided. That the starting material plays a role is confirmed here by the higher percentage of carbon and potassium in the Kalium muriaticum $30 \mathrm{cH}$ sample. This concentration was the highest compared with any other potentised sample and the carbon and silica percentage was also very high; this is part of the specific profile of this substance. ${ }^{30}$

\section{Dynamisation versus Dilution}

Whilst the dilution factor is part of the dynamisation process, the dynamisation itself produces detectable changes in the size, atomic composition and shapes of the resulting particles.
It is important to stress the fact that we recovered from the simply diluted preparations about twice the residual dry material as from a comparable potentised medicine. The dynamisation process not only reduces the amount of material but also induces specific chemistry, shapes and sizes. These important differences justify further studies into the behaviour of the solvent surrounding these specific particles. Some authors $^{43,44}$ have reported similar observations: they have identified electrically charged and stable water-clusters or dissipative structures in liquid water of low energy content.

\section{Limitations of the Current Study}

This study was carried out according to GPP. It would be helpful to examine these results with respect to good manufacturing practice and to compare them with results obtained using other batches and other starting material. More lyophilisations and more systematic measurements with SEM-EDS would be welcomed in the future. Ideally, it would be useful to examine full lines of dilutions/potentisation, measuring the changes occurring at each step. Comparisons of results obtained using different manufacturing lines of the same stocks and controls are needed in the future. A systematic comparison with preparations made in PET containers would also be helpful. Reproducibility by other laboratories using the same framework also needs to be demonstrated. To remain within our budget, we had to reduce the number of samples analysed and priority was given to high homeopathic potencies (HHP) when a significant particle count was identified. Most of the measurements were carried out on preparations without alcohol to ensure accurate results. Other techniques are required for which alcohol does not compromise the accuracy of measurement, so that a comprehensive picture of the nature of homeopathic medicines can be developed. Even though our measurements identified differences between homeopathic medicines and controls, many puzzles remain, such as the specificity of the signature between different homeopathic stocks of the same family (plant/metal/others), or between each dynamisation level, which cannot be addressed by this single study.

\section{Implications for Future Research}

To address the problem of plausibility ${ }^{11}$ of homeopathic medicines, more pharmacological studies are needed. The present measurements justify further research and demonstrate the importance of GPP and of excellent quality control for the MT. It also opens new perspectives for further research areas and for alternative explanations of the mechanism of action of homeopathic medicines. Research on homeopathic medicines must not remain anecdotal but should be integrated into the pharmaceutical training of future pharmacists. The DynHom project must continue and carry out more systematic particle measurements, as has already taken place with the NMR study. ${ }^{15}$

\section{Conclusions}

Using mass spectrometry (SP-ICP-MS) and DLS, we could not find the expected copper in the $4 \mathrm{cH}$ potentisation; therefore, we could not confirm the results previously obtained. ${ }^{1}$ For Gelsemium medicines, using sensitive chromatography (HPLC-UV), 
up to a dilution level of $6 \mathrm{dH}$ ( $3 \mathrm{cH}-10 \mathrm{e}-6)$, there was no significant difference in alkaloid content between a simple dilution and a homeopathic potency.

Using a step-by-step dilution or potentisation process, NTA findings revealed the presence of particles in all samples (except for pure water), even at the highest level of dilution; quantities were very low but measurable. The measurements showed large differences in particle quantities, mean particle sizes and SDs of the mean sizes between manufacturing lines of different starting material.

At the end of the lyophilisation process, free dry residues were collected and weighed. There was more material in simply diluted preparations than in samples potentised to the same level of dilution, and more than in the potentised pure water. The Gelsemium yielded the largest quantity of material (36 times more than from copper at the same potentisation, $30 \mathrm{cH}$ ). The existence of this material demonstrates that the step-by-step process used (dynamised or not) does not match with the theoretical expectations in a dilution process.

The shapes and chemistry of the collected material, observed with SEM-EDX, are differentiable between controls, starting material and manufacturing method. Further study with several and complete manufacturing lines are justified.

Highlights

- The nature of homeopathic medicines even in highest dilutions is identified using modern measurement methods.

- The presence of material in high-diluted homeopathic medicines invalidates the Avogadro/Loschmidt limit for homeopathic potentisations.

- Starting material is not identifiable in high homeopathic potentisations.

\section{Supplementary Files}

-Supplementary Fig. 1 Nanoparticles in lactose control $4 \mathrm{cH}$ pre-filtered (filter $100 \mathrm{~nm}$ ).

- Supplementary Fig. 2 Nanoparticles in Cuprum metallicum $4 \mathrm{cH}$ pre-filtered (filter $100 \mathrm{~nm}$ ).

- Supplementary Fig. 3 Nanoparticles in Cuprum metallicum $4 \mathrm{cH}$, impregnated pillules, diluted in water and dynamised again, filtered (filter $100 \mathrm{~nm}$ ).

- Supplementary Fig. 4 Comparison of particle dispersity index of Cuprum $4 \mathrm{cH}$ with lactose (control).

- Supplementary Fig. 5 Zeta potential Cuprum $4 \mathrm{cH}$ median values.

- Supplementary Fig. 6 Sempervirine chemical structure. - Supplementary Fig. 7 Gelsemine chemical structure.

- Supplementary Fig. 8 Nanoparticle tracking analysis-Size distribution curves of copper, Gelsemium sempervirens, and water controls (soda glass).

- Supplementary Fig. 9 Aqua pura $30 \mathrm{cH}$ (prepared in glass containers) originally magnified $\times 2500$.

- Supplementary Fig. 10 Cuprum 30cH (PET containers) originally magnified $\times 2000$.
-Supplementary Fig. 11 Argentum metallicum $30 \mathrm{cH}$ originally magnified $\times 2000$.

- Supplementary Fig. 12 Silica terra $30 \mathrm{cH}$ originally magnified $\times 2000$.

-Supplementary Fig. 13 Kalium muriaticum $30 \mathrm{cH}$ originally magnified $\times 2000$.

-Supplementary Fig. 14 Argentum metallicum $200 \mathrm{cK}$ originally magnified $\times 2000$.

- Supplementary Fig. 15 Silica terra 200 cK originally magnified $\times 2000$.

- Supplementary Fig. 16 Silica terra 10e-60 originallymagnified $\times 2000$.

-Supplementary Fig. 17 Cuprum 10e-60 originally magnified $\times 2500$.

- Supplementary Fig. 18 Gelsemium sempervirens 10e60 (simply diluted) originally magnified $\times 2000$.

-Supplementary Fig. 19 Argentum metallicum 10e-60 originally magnified $\times 2000$.

- Supplementary Fig. 20 Identified chemistry in dilutions/potentisations for the five most highly concentrated atoms in the different preparations.

-Supplementary Fig. 21 Identified chemistry in dilutions/potentisations for seven atoms with lower concentrations in the different preparations.

-Supplementary Fig. 22 Identified chemistry in dilutions/potentisations for five most highly concentrated atoms in comparable preparations and water control.

-Supplementary Fig. 23 Identified chemistry in dilutions/potentisations for five atoms with lower concentrations in the preparations expressed at the lowest comparable scale.

Conflict of Interest

None.

Funding

This study was funded by private donations from patients and doctors, with corporate support from UNIO HOMOEOPATHICA BELGICA (Belgian MD Homeopathic Union).

\section{Acknowledgements}

The required Gelsemium MT was provided by HEEL laboratories. The required copper stock was provided by REMEDY BANK cooperative company. Delvenne pharmacy allowed us to manufacture all the samples and PHARMAHOM (Belgian homeopathic pharmacists association) financed the manufacturing process. Lyophilisation and HPLC-UV analysis was undertaken at the pharmacognosy laboratory of UCL (Prof. Joëlle Leclercq). SYSMEX company and CODA-CERVA assisted us with the other measurements (MS-DLS-NTA-SEM/EDS). We thank them all.

The authors also wish to acknowledge the kind assistance of Pierre Dorfman for his help with the statistics. 


\section{References}

1 Chikramane PS, Kalita D, Suresh AK, Kane SG, Bellare JR. Why extreme dilutions reach non-zero asymptotes: a nanoparticulate hypothesis based on froth flotation. Langmuir 2012;28:15864-15875

2 Chikramane PS, Suresh AK, Bellare JR, Kane SG. Extreme homeopathic dilutions retain starting materials: a nanoparticulate perspective. Homeopathy 2010;99:231-242

3 Upadhyay RP, Nayak C. Homeopathy emerging as nanomedicine. Int J High Dilution Res 2011;10:299-310

4 Bell IR, Muralidharan S, Schwartz GE. Nanoparticle characterisation of traditional homeopathically-manufactured silver (Argentum Metallicum) medicines and placebo controls. J Nanomed Nanotechnol 2015;6:311

5 Ives JA, Moffett JR, Arun P, et al. Enzyme stabilization by glassderived silicates in glass-exposed aqueous solutions. Homeopathy 2010;99:15-24

6 Cartwright S. Pyridinium-N-phenolates as molecular probes of serially diluted and agitated solutions: preliminary results. Homeopathy 2014;103:65

7 Demangeat JL. Gas nanobubbles and aqueous nanostructures: the crucial role of dynamization. Homeopathy 2015;104:101-115

8 Mathie RT, Lloyd SM, Legg LA, et al. Randomised placebo-controlled trials of individualised homeopathic treatment: systematic review and meta-analysis. Syst Rev 2014;3:142

9 Mathie RT, Van Wassenhoven M, Jacobs J, et al. Model validity and risk of bias in randomised placebo-controlled trials of individualised homeopathic treatment. Comp Ther Med 2016;25:120-125

10 Editorial (2005). The end of homeopathy. Lancet 2005;366:690

11 Rutten L, Mathie RT, Fisher P, Goossens M, Van Wassenhoven M. Plausibility and evidence: the case of homeopathy. Med Health Care Philos 2013;16:3/525-532

12 European Pharmacopoeia Online 8.2. 2014. Available at: http:// online6.edqm.eu/ep801/mobile/

13 Demangeat JL. NMR water proton relaxation in unheated and heated ultrahigh aqueous dilutions of histamine: evidence for an air-dependent supramolecular organisation of water. J Mol Liq 2009;144:32-39

14 Demangeat JL. Nanosized solvent superstructures in ultramolecular aqueous dilutions: twenty years' research using water proton NMR relaxation. Homeopathy 2013;102:87-105

15 Van Wassenhoven M, Goyens M, Henry M, Capieaux E, Devos P. Nuclear Magnetic Resonance characterization of traditional homeopathically manufactured copper (Cuprum metallicum) and plant (Gelsemium sempervirens) medicines and controls. Homeopathy 2017;106:223-239

16 Tsukihara T, Aoyama H, Yamashita E, et al. Structures of metal sites of oxidized bovine heart cytochrome c oxidase at $2.8 \mathrm{~A}$. Science 1995;269:1069-1074

17 Hodiamont. Homéopathie et Physiologie. Baillère JB, ed. Paris: Similia; 1983

18 Hahnemann S. (1828). Chronic Diseases. Schmidt \& Kunzli eds. South Asia Books; 2005

19 Allen T. Encyclopedia of Pure Materia Medica. New York: Boericke \& Tafel; 1879

20 Bradford T. Index of Homeopathic Provings. New Delhi: B Jain Publishers; 2000

21 Duke J, Hughes R. Cyclopaedia of Drug Pathogenesy. London: B Jain Publishers; 1891

22 Allen HC. Allens Keynotes. New Delhi: B Jain Publishers; 2000

23 Dorfman P, Guillemain J, Nevy P, Tetau M. Double-blind drug pathogenesy of Cuprum metallicum 30CH. Cahiers de Biothérapie 1987;93:47-56

24 Mahata CR. Dielectric dispersion studies of some potentised homeopathic medicines reveal structured vehicle. Homeopathy 2013;102:262-267

25 Betello CF. Antioxidante effect in vitro of the homeopathic medicine Arsenicum album, Cuprum metallicum, Manganum and
Zincum metallicum. Thesis Faculdade de Ciências da Saude de São Paulo, Brazil; 2002

26 Smits T. Inspiring Homeopathy: Treatment of Universal Layers. ISBN 9789076189000; United States: Emryss; 2013

27 Van Wassenhoven M. First line medicine - Clinical Verification Verification of homeopathic symptoms. Cuprum metallicum. ISBN 978-2-87491-003-6; New Delhi: B Jain Publishers; 2008

28 Boericke W, Boericke OE. Homeopathic Materia Medica. ISBN 0766183882; Motilal Banarsidass; 1927

29 Santini R, Tessier M, Bellon P. First experimental arguments in favour of the effect of very weak doses of copper on digestive motricity in mice and rabbits. In: Ultra Low Doses. London, UK: Taylor \& Francis; 1991:3-10

30 Hariveau E, Nolen P, Holtzscherer A. A study of the effectiveness of ultra low doses of copper in the treatment of hemodialysisrelated muscle cramps. RCT. In: Doutremepuich C, ed. Ultra Low Doses. London: Taylor \& Francis; 1991:145-149

31 Vermeulen F, Johnston L. Plants. Homeopathic and Medicinal Uses from a Botanical Family Perspective. Glasgow, Scotland: Saltire Books. ISBN 978-0-955-90655-8; 2011

32 Mishra N, Muraleedharan KC, Paranjpe AS, Munta DK, Singh H, Nayak C. An exploratory study on scientific investigations in homeopathy using medical analyzer. J Altern Complement Med 2011;17:705-710

33 Marzotto M, Olioso D, Brizzi M, Tononi P, Cristofoletti M, Bellavite P. Extreme sensitivity of gene expression in human SH-SY5Y neurocytes to ultra-low doses of Gelsemium sempervirens. BMC Complement Altern Med 2014; 14:104

34 Dimpfel W, Biller A. In vivo and in vitro neurophysiological findings in the rat in the presence of Coffea D6, Gelsemium D4 and Veratrum D6 extracts. Scientific Framework of Homeopathy; 2014. LMHI. Available at: http://www.lmhi.org/Article? menuId $=13 \&$ subMenuId $=41$

35 Meyer L, Boujedaini N, Patte-Mensah C, Mensah-Nyagan AG. Pharmacological effect of gelsemine on anxiety-like behavior in rat. Behav Brain Res 2013;253:90-94

36 Van Wassenhoven M. First line medicine - Clinical verification Verification of homeopathic symptoms. ISBN 978-2-87491-0036; New Delhi: B Jain Publishers; 2008

37 Magnani P, Conforti A, Zanolin E, Marzotto M, Bellavite P. Doseeffect study of Gelsemium sempervirens in high dilutions on anxiety-related responses in mice. Psychopharmacology (Berl) 2010;210:533-545

38 Bellavite P, Conforti A, Marzotto M, et al. Testing homeopathy in mouse emotional response models: pooled data analysis of two series of studies. Evid Based Complement Alternat Med 2012; 2012:954374

39 Dorfman P, Tetau M. Applications cliniques de la recherche pharmacologique. Cahiers de Biothérapie ${ }^{\circ} 125$; Eds Similia Paris, France; 1993

40 Paris A, Schmidlin S, Mouret S, et al. Effect of Gelsemium 5CH and $15 \mathrm{CH}$ on anticipatory anxiety: a phase III, single-centre, randomized, placebo-controlled study. Fundam Clin Pharmacol 2012; 26:751-760

41 Bono I, Delgiudice E, Gamberale L, Henry M. Emergence of the coherent structure of liquid water. Water 2012;4:510-531

42 Albrigo LG, Szafranck RC, Childers NF. The role of Molybdenum in Plants and soils. Climax Molybdenum Co., Supplemental volume 1966. Available at: http://www.climaxmolybdenum.com/ Phenix USA

43 Lo S, Geng X, Gann D. Evidence for the existence of stable-waterclusters at room temperature and normal pressure. Phys Lett $A$ 2009;373:3872-3876

44 Elia V, Germano R, Napoli E. Permanent dissipative structures in water: the matrix of life? Experimental evidences and their quantum origin. Curr Top Med Chem 2015;15:559-571

45 Peck R, Olsen C, Devore JL. (2008). Introduction to Statistics and Data Analysis, 3rd ed. Available at: https://www.cengage.co.uk/ 